\title{
Review \\ Electrochemical Devices to Monitor Ionic Analytes for Healthcare and Industrial Applications
}

\author{
Sue-Yuan Fan ${ }^{1,2,+}$, Sucharita Khuntia ${ }^{1,2,+}$, Christine Heera Ahn ${ }^{3}{ }^{\mathbb{D}}$, Bing Zhang ${ }^{4}$ and Li-Chia Tai ${ }^{1,2, *}$ \\ 1 Department of Electrical and Computer Engineering, National Yang Ming Chiao Tung University, \\ Hsinchu 30010, Taiwan; syfan.c@nycu.edu.tw (S.-Y.F.); sucharita.khuntia.ee10@nycu.edu.tw (S.K.) \\ 2 Institute of Electrical and Control Engineering, National Yang Ming Chiao Tung University, \\ Hsinchu 30010, Taiwan \\ 3 John A. Paulson School of Engineering and Applied Sciences, Harvard University, \\ Cambridge, MA 02138, USA; christineahn@g.harvard.edu \\ 4 Lam Research, Fremont, CA 94538, USA; zhangbing@berkeley.edu \\ * Correspondence: j.tai@nycu.edu.tw \\ + These authors contributed equally to this work.
}

Citation: Fan, S.-Y.; Khuntia, S.; Ahn, C.H.; Zhang, B.; Tai, L.-C.

Electrochemical Devices to Monitor Ionic Analytes for Healthcare and

Industrial Applications. Chemosensors 2022, 10, 22. https://doi.org/

$10.3390 /$ chemosensors 10010022

Academic Editor: Nicole

Jaffrezic-Renault

Received: 24 November 2021

Accepted: 29 December 2021

Published: 6 January 2022

Publisher's Note: MDPI stays neutral with regard to jurisdictional claims in published maps and institutional affiliations.

Copyright: (C) 2022 by the authors. Licensee MDPI, Basel, Switzerland. This article is an open access article distributed under the terms and conditions of the Creative Commons Attribution (CC BY) license (https:// creativecommons.org/licenses/by/ $4.0 /)$.

\begin{abstract}
Recent advances in electrochemical devices have sparked exciting opportunities in the healthcare, environment, and food industries. These devices can be fabricated at low costs and are capable of multiplex monitoring. This overcomes challenges presnted in traditional sensors for biomolecules and provides us a unique gateway toward comprehensive analyses. The advantages of electrochemical sensors are derived from their direct integration with electronics and their high selectivity along with sensitivity to sense a wide range of ionic analytes at an economical cost. This review paper aims to summarize recent innovations of a wide variety of electrochemical sensors for ionic analytes for health care and industrial applications. Many of these ionic analytes are important biomarkers to target for new diagnostic tools for medicine, food quality monitoring, and pollution detection. In this paper, we will examine various fabrication techniques, sensing mechanisms, and will also discuss various future opportunities in this research direction.
\end{abstract}

Keywords: electrochemical devices; chemical sensors; ionic detection; health monitoring; environmental monitoring

\section{Introduction}

The charged ionic species, such as electrolytes $\left(\mathrm{Na}^{+}, \mathrm{K}^{+}, \mathrm{Cl}^{-}\right)$and heavy metals $\left(\mathrm{Pb}^{2+}, \mathrm{Cu}^{2+}, \mathrm{Cd}^{2+}, \mathrm{Zn}^{2+}, \mathrm{Hg}^{2+}\right)$, play key roles in physiological processes for biological developments, including neural communication networks and biofeedback systems for cardiovascular regulation [1-9]. These charged species regulate the $\mathrm{pH}$ level in water ecosystems and help in plant growth for the environment [5]. However, disproportionate concentration of ionic species can be toxic for many biological processes [1-3,5,7]. As an example, heavy metal concentration in the human body is associated with a higher risk for Alzheimer's disease [2]. High concentrations of these heavy metal species are often caused by pollution from modern factories, as well as hazardous substances from the developments of agriculture [1-3]. Toxic ionic species can also be absorbed into the body. Mercury substances are found in food sources involving aquatic species and in day-to-day life [2]. The ions from industrial waste and old piping can make their way into food and water sources [4]. Therefore, the potential value of continuous monitoring and tracking down ionic analytes are significant. In preventive healthcare, it is essential to develop ion-sensitive devices that can track and monitor the ionic concentration levels that have important implications on the health of an individual.

In this paper, we focus on the application of ion-selective devices used in diverse scenarios. Electrochemical devices enable the measurement of a wide variety of ions, such 
as hydrogen ions, electrolytes, heavy metals, and nutrients [5-8]. For instance, one of the common methods to measure $\mathrm{pH}$ is using glass electrodes. Figure 1 shows various usage of ion-selective devices. In recent years, they are extensively used in healthcare, environmental monitoring, food quality assessment, agriculture cultivation, and drug tests $[2,5,7,9]$. These electrochemical devices can be fabricated as electrochemical sensors through roll-to-roll (R2R) printing, physical vapor deposition (PVD), and semiconductor compatible processes [9]. They are capable of multiplex sensing, which provides users a pathway toward comprehensive analyses.
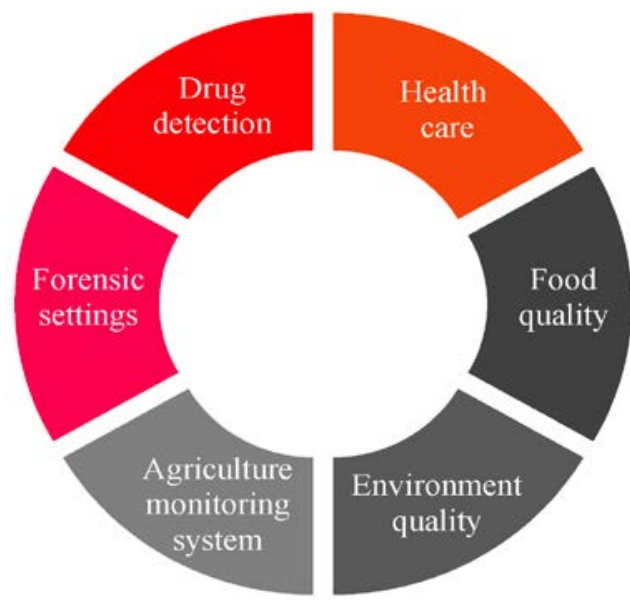

Figure 1. Wide application of sensors for ionic analytes.

Developing cost-effective and high-throughput methods of fabricating sensing components are critical for the commercialization of one-time throw electrochemical devices. In various available printing techniques, such as R2R gravure printing, large-scale production of low-cost and robust devices can become possible. The simple printing mechanism of R2R gravure allows faster printing speeds and also provides superior resolution, consistency over the screen, offset, and flexography printing techniques $[9,10]$. Due to their promising usage, the advancement of integrated electrochemical devices is fueled by rapidly growing research. They consist of an ionized functional layer, such as film or membrane, that is selectively responsive to targeted ions and electrochemical transducers to relay chemical signals to electrical signals when target analyte ions are in contact with the layer. The commonly used electrochemical sensing technologies are based on potentiometric, voltammetric, capacitance, and impedance measurements [11-19]. Heavy metals are important indicators of the toxicity of an environment and human health condition. Human body fluids (such as blood, sweat, and urine) contain various metabolites, electrolytes, proteins, and heavy metals. Research has shown that various heavy metals can be found in human body fluids, which are closely related to human health status $[9,11]$. For instance, high $\mathrm{Cu}^{2+}$ accumulation in the human body can lead to Wilson's disease [4]. Additionally, $\mathrm{Pb}^{2+}$ and $\mathrm{Hg}^{+}$are toxic substances on human body systems, including cardiovascular, immunological, and nervous systems [20-25]. Some studies are developing electrochemical sensors based on organic conducting polymers, such as composites with carbon nanotubes (CNTs), to detect trace heavy metal ions in water [26]. CNTs have good properties such as chemical, mechanical, electrical, and environmental stability. Graphene-based materials are promising due to their low electronic noise and zero bandgap. They have high electron mobilities which are essential for heavy metal detection $[27,28]$. Organic conducting polymers (OCPs), such as polypyrrole, polyphenylene, polyaniline, polyacetylene, polythiophene, etc., have advanced electrochemical properties toward metal ions detection [29]. Because of their collective redox properties, OCPs have good sensitivity to minor electrochemical perturbations [30].

In the following sections, we report sensor types, materials, fabrication processes, and sensing mechanisms for ion-selective devices. Then, we discuss how electrochemical 
sensors for ionic analytes can be adopted for various applications such as health monitoring, environment analysis, water quality, agricultural cultivation, production industries, and forensic settings. In Section 4, we review variations of these electrochemical sensors with enhanced capabilities through integration with microfluidic devices, energy-harvesting, and self-powered functions. Moreover, we will further discuss different future research directions in this area.

\section{Sensor Types and Mechanisms}

Sensors for ions target a wide variety of analytes. They can be categorized as anions and cations. There are also special types that are worth special attention, such as heavy metal ions, nutrient ions, and electrolytes.

\subsection{Types of Ionic Analytes}

\subsubsection{Cations}

Cations are important in biological phenomena that respond to physiological stimuli. In biomimetic nanofluidic gating systems, smart bio-inspired devices can be developed to monitor the concentrations of cations that are related to our daily life and environment, such as $\mathrm{H}^{+}, \mathrm{Na}^{+}, \mathrm{K}^{+}$[31-36]. Jean-Philippe Ndobo-Epoy et al. [37] reported the development of a new iridium oxide nanometer $\mathrm{pH}$ sensor with high reproducibility. To ensure good chemical insulation during the manufacturing process of making iridium nanotips, a xylene insulating layer was used to cover the nanoelectrode tips, and a gallium focused ion beam was also used to open a hole of $100 \mathrm{~nm}$ diameter to form a sensing area for transmission. To produce a stable $\mathrm{pH}$ response, the iridium tip was oxidized in an oxygen atmosphere for $12 \mathrm{~h}$. The measurement procedure used an Atomic Force Microscope (AFM) to control the distance between the sample and the nanosensor. Upon immersing the device in the buffer solution, a Nernstian behavior (slope $59.2 \mathrm{mV} / \mathrm{pH}$ ) was shown in a calibration curve in the range from $\mathrm{pH} 3$ to 14. Wen-Ding Huang et al. [38] proposed another iridium oxide sensing film for $\mathrm{pH}$ detection. In their work, the sensitivity of the sensor matched with the theoretical Nernstian response and showed a rapid response to the $\mathrm{pH}$ level. Figure $2 \mathrm{~A}$ shows a fabricated device containing three pairs of miniaturized working $\mathrm{IrO}_{\mathrm{x}}$ and reference $\mathrm{Ag} / \mathrm{AgCl}$ electrodes on a polyimide substrate to detect $\mathrm{pH}$ from 1.5 to 12 . The electrodes were fabricated in three pairs (each pair with its working and reference electrode) that are separated from each other by $5 \mathrm{~mm}$, which defined the sensing spatial resolution.

Longjiao Zhu et al. [39] have developed a universal electrochemical biosensor that detects $\mathrm{Cr}^{3+}$ ions and microRNA via synthetic nanochannels as capture probes. This work synthesizes small diameters of nanochannel with anodized aluminum oxide (AAO) porous film and high channel density. The AAO creates a larger surface area to respond to these fastchemical reactions. Wei Gao et al. [40] have demonstrated a wearable microsensor array to monitor heavy metals in body fluids. This work shows a flexible wearable microsensor array that can allow simultaneous and selective sensing of various heavy metals in human sweat, such as $\mathrm{Cd}^{2+}, \mathrm{Pb}^{2+}, \mathrm{Zn}^{2+}, \mathrm{Hg}^{+}$, and $\mathrm{Cu}^{2+}$. The flexible microsensor arrays demonstrate outstanding repeatability and stability for heavy metal detection. They also integrate with a temperature sensor for real-time compensation of the sensing signals to ensure reliable and accurate measurements. As shown in Figure 2B, the device consists of a flexible working electrode (WE) and counter electrode (CE) array, a printed circuit board, and a polydimethylsiloxane (PDMS) well on polyethylene terephthalate (PET). In this work, the authors demonstrate the sensitivities for $\mathrm{Pb}^{2+}, \mathrm{Cu}^{2+}$, and $\mathrm{Hg}^{+}$to be $1.4,4.1$, and $2.9 \mathrm{nA} \cdot \mathrm{L} / \mu \mathrm{g}$, respectively, through stripping voltammograms with $\mathrm{Au}$ or $\mathrm{Bi}$ as working microelectrodes. Ion sensors are used to detect ions in different matrices including body fluids, with urine as one commonly used sample type in clinical testing.

The composition in urine, such as urea, uric acid (UA), creatinine, and hydrogen ions, are important biomarkers for the diagnosis of urethritis, kidney disease, and electrolyte disorders [41]. Jiang Liu et al. [41] developed an electrochemical sensor that was easy to manufacture and with the simple detection principle of cyclic voltammetry and open 
circuit potential measurement in urine. This device was capable of detecting urea, and $\mathrm{pH}$ from urine on the same working electrode, and the range of $\mathrm{pH}$ detection was 4.0-8.0. As shown in Figure 2C, a tip-shaped sensor system is composed of three main parts, namely the connector at the top of the device, the cylindrical electrode setting tube at the middle part, and the conical suction sheet at the bottom. The design of the middle tube has three inner grooves. Those grooves are suitable for placing different materials for the working electrode, counter electrode, and reference electrode. The sensor adopts a square wave voltammetry technique to identify the oxidation peak of UA. While the peak current gives information on the concentration of $\mathrm{UA}$, the variation of $\mathrm{pH}$ causes a shift in the oxidation peak of UA, and the degree of shifting becomes the basis of $\mathrm{pH}$ measurement. When $\mathrm{S} / \mathrm{N}=3$, the sensitivity of $\mathrm{pH}$ detection in urine is $73 \mathrm{mV} / \mathrm{pH}$, meaning that, for every unit change of $\mathrm{pH}$ level, it causes the oxidation peak of UA to shift by $73 \mathrm{mV}$. This sensing method is a new application of electrochemical technology for point-of-care testing (POCT).

\subsubsection{Anions}

The detection of anions (such as $\mathrm{PO}_{4}{ }^{3-}, \mathrm{NO}_{3}{ }^{-}, \mathrm{F}^{-}, \mathrm{Cl}^{-}$) is essential for the determination of important areas such as water quality, physiological status, and soil conditions monitoring [42,43]. Piotr Gołębiewski et al. [44] presented a high selectivity and sensitivity sulfate ion sensor at $\mathrm{pM}\left(10^{-12} \mathrm{~mol} / \mathrm{dm}^{3}\right)$ level. The device comprises a cyclopeptidedipyrromethene- $\mathrm{Cu}^{2+}$ or $\mathrm{Co}^{2+}$ sensing layer on a gold electrode. The sensor can detect sulfate ions in the water without adding an external redox marker to the test solution, and electrochemical anionic sensing happens on the surface of the functional film of an electrode. This work also considers the contact angles between water droplets and the surface monolayers on the electrodes as a key parameter once an analyte adsorbs onto the functional film. The abovementioned sensor shows detection limits of $0.10 \mathrm{pM}$ $\left(\mathrm{Cu}^{2+}\right.$-containing electrode) and $0.14 \mathrm{pM}\left(\mathrm{Co}^{2+}\right.$-containing electrode), and selectivities (defined as the ratio of the slopes of the calibration curves obtained for the target ion and the interfering ion) of $0.84\left(\mathrm{Cu}^{2+}\right.$-containing electrode) and $0.42\left(\mathrm{Co}^{2+}\right.$-containing electrode).

Sam Emaminejad, et al. [45] proposed a device that shows sensitivities of 63.2 and $55.1 \mathrm{mV}$ per decade of concentration to $\mathrm{Na}^{+}$and $\mathrm{Cl}^{-}$, measured in $10-160 \mathrm{mM} \mathrm{NaCl}$ solutions. The repeatability is also demonstrated after over $6 \mathrm{~h}$ of long-term and continuous measurement in 20,40, and $80 \mathrm{mM} \mathrm{NaCl}$ solutions. In Figure 2D, the left side shows electrodes of iontophoresis sweat sensors that target $\mathrm{Na}^{+}$and $\mathrm{Cl}^{-}$and form a stable sensorskin contact. The flexible PET is chosen as substrates for the patterned electrodes, where the middle part illustrates the independent and switchable mode between the iontophoresis process and sweat sensing. Polyvinyl butyral (PVB) was selected to coat the reference electrode to provide stability under different voltages. The right side of the figure shows electrochemical sensors' responses in $\mathrm{NaCl}$ solutions.

Md. Azahar Ali et al. [46] introduced a tiny sensor that can be used for long-time continuous monitoring of nitrate in the soil. Since the poly(3-octyl-thiophene) and molybdenum disulfide $\left(\mathrm{POT}-\mathrm{MoS}_{2}\right)$ composite material has high hydrophobicity and redox properties, it is very suitable for use as the sensing layer in nitrate ion detection. The sensor has two round-shaped, $5 \mathrm{~mm}$ diameter, working and reference electrodes based on copper. For the working electrode fabrication, Au layer $(100 \mathrm{~nm}$ thick and $5.2 \mathrm{~mm}$ diameter) was deposited on top via electron beam evaporation process. Then, POT-MoS 2 and nitrate ion-selective membranes were dispensed on top of the Au surface by an automated fluid-dispensing robot. For the reference electrode fabrication, the Ag layer was first prepared with the same evaporation process above $(500 \mathrm{~nm}$ thick and $5.2 \mathrm{~mm}$ diameter) and then screen-printed with $\mathrm{Ag} / \mathrm{AgCl}$. Thus, after WE and $\mathrm{RE}$ are fabricated, direct coating of molybdenum disulfide $\left(\mathrm{MoS}_{2}\right)$, poly(3-octylthiophene-2,5-diyl) (POT), poly(3-octyl-thiophene), and molybdenum disulfide $\left(\mathrm{POT}-\mathrm{MoS}_{2}\right)$ was performed on the electrode through high-precision robotic arm automatic distributor to complete the production of the sensing electrodes. The sensor with POT-MoS 2 produces better selectivity and sensitivity compared with those prepared with $\mathrm{MoS}_{2}$ or POT. The results show that the 
sensing device developed in this study can be deployed in the soil to monitor the nitrate for about 4 weeks. Furthermore, the authors noted that, by replacing nitrate sensing film with another ion-selective film, the sensor can potentially be used to detect other different nutrients in the soil, such as sulfate, phosphate, and potassium. These ions are all essential nutrients for plant growth and agricultural productivity. The continuous measurement of nutrients has important potential applications in plant breeding, plant biology, production agriculture, and environmental science. Figure 2E shows the manufacturing of an all-solid soil nitrate sensor. The left side shows the high-precision automatic fluid distribution robot, which can distribute the POT-MoS 2 material on the circular Au electrode, and the right side shows an image of the fabricated device.

\subsubsection{Multiplexed Sensing of Both Cations and Anions}

The multiplexed sensing of both cations and anions such as $\mathrm{Ni}^{2+}, \mathrm{Co}^{2+}, \mathrm{Mg}^{2+}, \mathrm{Ba}^{2+}$, $\mathrm{PO}_{4}{ }^{3-}, \mathrm{NO}_{3}{ }^{-}, \mathrm{K}^{+}$, and $\mathrm{F}^{-}$are published in the literature [47], while the development of a potentiometric silver ion-selective electrode is also reported [48]. An amendable sensing platform that can target various types of ions is quite attractive for practical applications. In particular, human sweat contains a rich amount of cations and anions and represents an important target of interest for multiplexed sensing to capture a complete picture of a person's physiological state. Hnin Yin Yin Nyein et al. [49] presented an efficient ion detection system to analyze sweat secretion of multiple components such as $\mathrm{pH}, \mathrm{Na}^{+}$, $\mathrm{K}^{+}, \mathrm{Cl}^{-}$, and sweat rate. It integrates microfluidic channels and fabricates sensors on PET. This work provides a solution to simultaneously monitor different types of analytes and minimize the averaging effect by allowing fresh sweat to be measured. As shown in Figure 2F, the sensor is composed of a spiral microfluidic channel, a pair of parallel $\mathrm{Au}$ electrodes, an insulation layer made of parylene- $\mathrm{C}$, and $\mathrm{Na}^{+}$sensing electrodes. The sweat sensing data can be transmitted to a cellphone via Bluetooth. From the measured data, the output result can be obtained from on-body sweat analysis of $\mathrm{pH}, \mathrm{K}^{+}$, and $\mathrm{Cl}^{-}$through the sweat sensing patch during a stationary cycling period of the volunteer. The reservoir is designed to collect sweat for multiplexed detection of analytes in the sweat, as shown on the right part of the figure.

\subsection{Electrode Type}

Some commonly used electrodes are glassy carbon electrodes, screen-printed electrodes, and roll-to-roll printed electrodes. Selective electrode is a key part in the electrochemical sensor, such as the potentiometric nitrate ion-selective electrodes being reported [46]. Here, we will provide more detailed discussion of each electrode type.

\subsubsection{Glassy Carbon Electrodes}

Glassy carbon electrodes (GCE) have wide usages in the detection of ions, such as heavy metal ions, which pose danger to public health as well as on our environment. For example, Reda M. El-Shishtawy et al. [50] proposed an approach to fabricate a $\mathrm{Cd}^{2+}$ ion sensor based off Schiff base, 1,1'-(biphenyl-4,4'-diylbis(azan-1-yl-1-ylidene))bis(methan-1yl-1-ylidene) dinaphthalen-2-ol (BZNA). A Nafion/glassy carbon electrode was covered with a thin layer of the synthesized BZNA to selectively detect $\mathrm{Cd}^{2+}$ ion in an aqueous environment. When voltammetry was adopted for detecting $\mathrm{Cd}^{2+}$, the measured sensitivity, limit of quantification (LOQ), limit of detection (LOD), and the linear dynamic range (LDR) of $\mathrm{Cd}^{2+}$ ions were found to be $2.93 \mu \mathrm{A} \mu \mathrm{M}^{-1} \mathrm{~cm}^{-2}, 106.67 \mathrm{pM}, 32.0 \pm 1.62 \mathrm{pM}$, and from $0.1 \mathrm{nM}$ to $0.1 \mathrm{mM}$, respectively. This novel approach enables different methodologies to the heavy metal ion detection process in the fields of healthcare and the environment. In one example, glassy carbon electrode (GCE)/platinum (Pt)/dealuminated (D)-mordenite electrode was selected for heavy metal ions detection such as $\mathrm{Hg}^{2+}$. In this work, the detection limit was $3.4 \mathrm{nM}$, and the sensitivity was $11.2598 \mu \mathrm{A} \mu \mathrm{M}^{-1} \mathrm{~cm}^{-2}$ [51]. The detection of $\mathrm{Pb}^{2+}$ was performed with glassy carbon electrode modified by polyvinyl alcohol/chitosan-thermally reduced graphene composite and via anodic stripping voltam- 
metry [52]. A similar detection of $\mathrm{Pb}^{2+}$ was performed with glassy carbon electrode with modification by $\mathrm{rGO} / \mathrm{g}-\mathrm{C}_{3} \mathrm{~N}_{4}$ [53] and through modifying glassy carbon electrode with $\mathrm{Bi} /$ carboxyphenyl [54]. Afzal Shah et al. [55] designed a sensor to detect mercury and thallium, which have extensive use in thermostatic devices due to the mercury/thallium alloy's ability to withstand low temperature. The authors functionalized a glassy carbon electrode with amino acid that lowers the detection limit (the amino acid serves as a mediator that has strong interactions with the metal ions) to detect thallium and mercuric ions. Through electrochemical impedance spectroscopy, square wave anodic stripping voltammetry (SWASV), cyclic voltammetry (CV), and chronocoulometry, the limit of detection for $\mathrm{Hg}^{2+}$ and $\mathrm{Tl}^{+}$were 0.23 and $0.175 \mathrm{nM}$. These techniques that were based on a glycine modified glassy carbon electrode (Gly-GCE) demonstrated a greener and cost-effective detection approach with portability and rapid responsiveness.

\subsubsection{Screen-Printed Electrode}

Several kinds of ions sensing approach through screen-printed electrode were proposed. Prashanth Shivappa Adarakatti et al. [56] designed Calixarene bulk modified screenprinted electrodes, which were fabricated and utilized as electrochemical sensors toward the measurement of toxic metal ions such $\mathrm{Pb}^{2+}, \mathrm{Cu}^{2+}$, and $\mathrm{Hg}^{2+}$ within the environmental samples. In another paper, Tamer Awad Ali et al. [57] proposed a method for fabricating screen-printed electrode modified with gold nanoparticles. The detection limit was found to be $5.3 \times 10^{-10} \mathrm{~mol} \mathrm{~L}^{-1}$ for $\mathrm{Cu}^{2+}$ in water. These electrodes showed remarkable selectivity for $\mathrm{Cu}^{2+}$ over a wide variety of metal ions. Claudia Núñez et al. [58] developed an electrochemical biosensor for $\mathrm{As}^{3+}$ determination through immobilization of the Alcaligenis faecalis bacteria on gold nanoparticle-modified screen-printed carbon electrode. To improve the performance of the biosensor, the number of bacteria, the amount of cross-linker (glutaraldehyde), and the incubation time applied were optimized. María A Tapia et al. [59] prepared a bismuthene-modified carbon-based screen-printed electrode with the advantage of the strong features of exfoliated layered bismuth and differential pulse anodic stripping voltammetry for metal ions detection. Vincenzo Mazzaracchio et al. [60] designed screenprinted electrodes for sodium detection in sweat. These electrodes were easily modified by drop casting with selective membrane cocktail along with nanomaterial carbon black (for the working electrode) and with a polyvinyl butyral-based membrane (for the reference electrode). The carbon black-based sensor used for the detection of sodium ions has a detection limit of $63 \mu \mathrm{M}$.

Nowadays, there have been many efforts to construct miniaturized potentiometric sensors. The ion functionalized film-coated electrodes have the merits of simple construction and good linear range. Hence, these types of devices are commonly used for the determination of many ions, such as nitrate, sodium, and potassium ions. A disadvantage of this type of device is its poor reproducibility during sensing and sensor drift. That may be related to the poorly defined charge transfer at the interface of ion-sensitive membrane and conducting substrate $[61,62]$. Hence, the selection of a suitable functionalized film is essential. Meanwhile, the cost factor is another consideration of mass production for a one-time disposable screen-printed biosensor.

R. Zielińska et al. [63] selected a polypyrrole polymer film and fabricated electrode foil layers via screen-printed procedure to produce a potentiometric chloride sensor, with the lowest measured detection limit at $3.2 \mu \mathrm{M}$ (linear range: $10^{-1}$ to $10^{-5} \mathrm{M}$ ). For potentiometric measurements with liquid ion-selective electrodes and the analogues of solid-state electrodes, screen-printing technology can be a useful way for mass production. The technology also holds promises to produce integrated potentiometric devices that can be leveraged toward disposable sensors and flow-injection analysis [64]. 

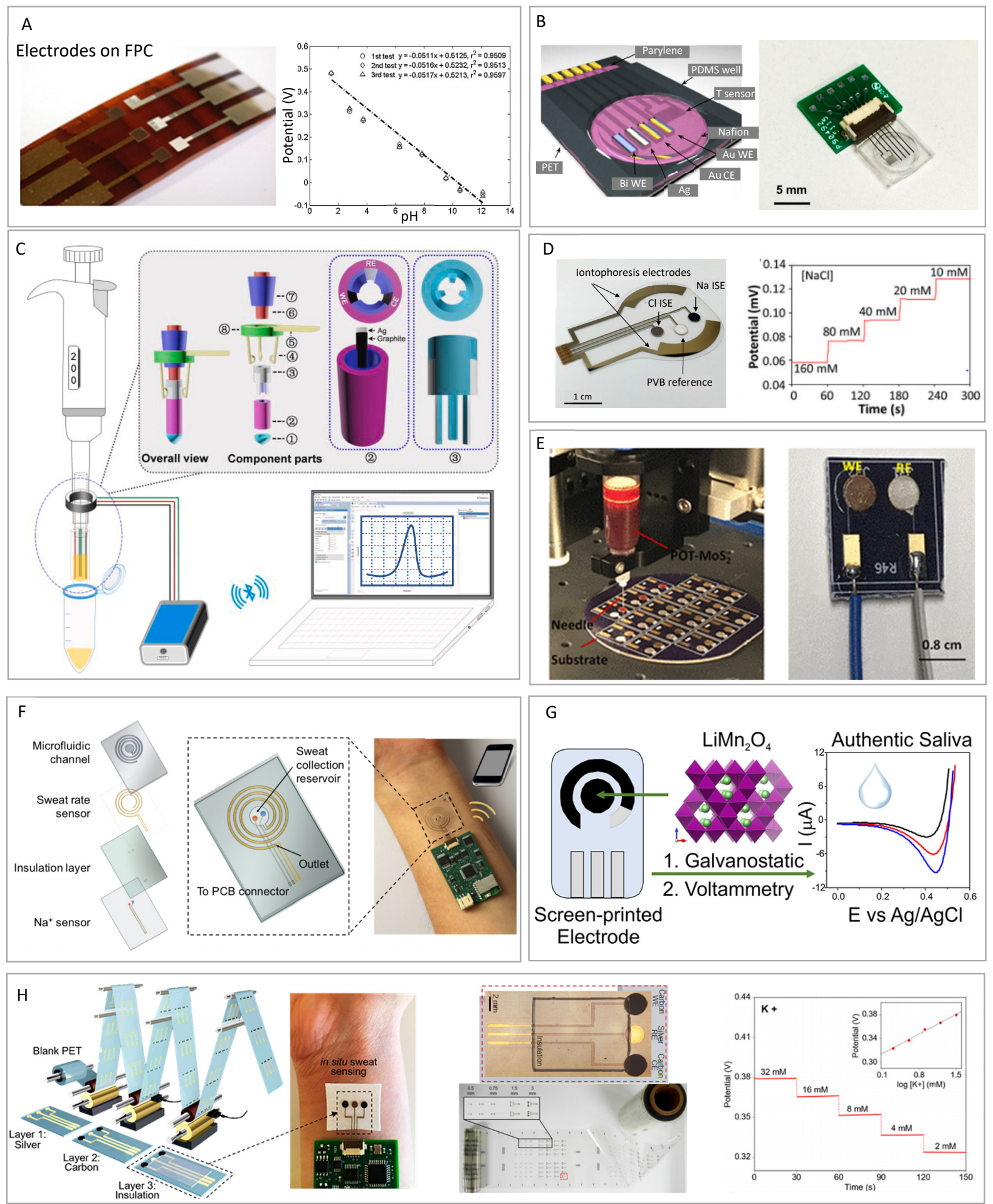

Figure 2. (A) From left to right, shows a fabricated device containing three pairs of electrodes and pH sensitivity on a flexible printed circuit (FPC) board. Reproduced with permission. Copyright 2011, Elsevier [38]. (B) From left to right, schematic showing a printed circuit board (PCB) connector interfacing with a multiplexed microsensor array with working electrode (WE) and counter electrode (CE) on a polyethylene terephthalate (PET) platform. The entire device can be covered with a polydimethylsiloxane (PDMS) material to create a well for sweat collection. Reproduced with permission. Copyright 2016, American Chemical Society [40]. (C) Schematic diagram of a tip-shaped sensor system: 1 . conical nozzle, 2 . electrode tube with three electrode strips, 3 . connector, 4 . connect the electrode, 5. platinum cable of the potentiostat, 6 . pipette nozzle, 7 . outer sleeve, 8 . the sleeve fixes the cable on the pipette. Reproduced with permission. Copyright 2021, Elsevier [41]. (D) From 
left to right, schematic of ion-selective electrodes (ISEs) and a reference electrode with polyvinyl butyral (PVB) material. The sweat sensing device can measure $\mathrm{Na}^{+}$and $\mathrm{Cl}^{-}$. Reproduced with permission. Copyright 2017, National Academy of Sciences [45]. (E) The manufacture of an allsolid soil nitrate sensor. Left side, the high-precision automatic fluid distribution robot distributes poly(3-octyl-thiophene) and molybdenum disulfide $\left(\mathrm{POT}-\mathrm{MoS}_{2}\right)$ nanocomposite on the circular $\mathrm{Au}$ electrode. Right side shows photos of the equipment. Copyright 2019, American Chemical Society [46]. (F) From left to right, the explosion plot of the sensing device, an ion-selective device with integrated circuits on PCB. Reproduced with permission. Copyright 2018, American Chemical Society [49]. (G) From left to right, shows a screen-printed electrode, lithium manganese oxide $\left(\mathrm{LiMn}_{2} \mathrm{O}_{4}\right)$, and electrochemical detection of $\mathrm{Li}^{+}$in authentic human saliva. Reproduced with permission. Copyright 2019, American Chemical Society [65]. (H) From left to right, shows R2R printed electrodes, R2R gravure printing of electrode arrays on flexible PET substrate. To print electrode arrays, carbon ink (provides stability under high operating potential) is deposited on top of silver (provides good conductivity). The characterization curve is shown on the right. Reproduced with permission. Copyright 2018, American Chemical Society [9].

Alex L. Suherman et al. [65] developed an electrochemical ion sensor for the detection of $\mathrm{Li}^{+}$from human saliva. Lithium manganese oxide (LMO) was used to modify glassy carbon electrodes (LMO-GCEs) and screen-printed electrodes (LMO-SPEs), and linear stripping voltammetry (LSV) was used as the sensing method to detect $\mathrm{Li}^{+}$. The sensor can analyze a sample within 3 min from LSV measurements, where the measurable limit was $50.0 \mu \mathrm{M}$ in both synthetic saliva samples and $\mathrm{LiClO}_{4}$ aqueous solutions. This research demonstrated the capability of detecting lithium ions $\left(\mathrm{Li}^{+}\right)$with low concentrations, good linearity, and high reproducibility (relative standard deviation $<7 \%$ ). Figure $2 \mathrm{G}$ shows the lithium manganese oxide-screen-printed electrodes, lithium manganese oxide $\left(\mathrm{LiMn}_{2} \mathrm{O}_{4}\right)$, and the detection of $\mathrm{Li}^{+}$in authentic human saliva. The sensing technique is based on the galvanostatic delithiation of LMO where the current is kept at a constant value during measurement, followed by a linear stripping voltammetry to detect the $\mathrm{Li}^{+}$ion.

\subsubsection{Roll-to-Roll Printed Electrode}

The production of high throughput and cost-effective biosensors is needed due to the rising importance of noninvasive health monitoring technology. Mallika Bariya et al. [9] presented a roll-to-roll (R2R) gravure printing technique to fabricate biosensors. This technique enables higher throughput, lower cost production, and robustness for electrochemical sensing applications. These R2R gravure printed electrodes are designed under a diverse range for noninvasive biosensing applications that are geared toward point-of-care health monitoring and diagnosis. In their work, they successfully achieved robust biosensing with a range of sensing applications for $\mathrm{pH}$, electrolytes, heavy metals, and other targets. The devices they created allow ionic sensing functionality and access to biofluids noninvasively. This technology is suitable for disposable sensors for personalized, in situ, and real-time health monitoring. They demonstrated a transferrable technology that enables mass production at low costs. Figure $2 \mathrm{H}$ shows biocompatible sensing electrode arrays, which are fabricated through R2R gravure printing technology, the device size, and the density of fabricated components can be controlled. The middle side shows electrodes on a PET substrate under scanning electron microscopy. The sensor can be functionalized to respond to different ions $\left(\mathrm{H}^{+}, \mathrm{K}^{+}, \mathrm{Na}^{+}, \mathrm{Cu}^{2+}\right)$, with an example such as $\mathrm{K}^{+}$shown on the right side.

Wookyu Lee et al. [10] reported an active matrix based single-walled carbon nanotubes (SWCNTs) with 9.3 points per inch (ppi) resolution by using a R2R gravure printing process. In this work, they obtained a device yield above $98 \%$ and extracted the important scalability factors such as gate electrode widths (GWs) and channel lengths (CLs) under the given overlay printing registration accuracy (OPRA). By the lamination of a pressure sensitive rubber on the SWCNT-Thin-Film-Transistor active matrices, the authors achieved multi- 
touch sensor arrays. This technique overcomes the registration barrier of printing each layer. Lee's work contributed to the development of an R2R mass production technique, which could have the potential to be used for fabricating ionic sensors.

\subsection{Sensing Mechanisms for Ion-Selective Devices}

The sensing mechanism for ion detectors is often implemented with techniques such as potentiometry, cyclic voltammetry $(\mathrm{CV})$, square wave anodic stripping voltammetry (SWASV), and some variations of these aforesaid methods. Here, we will discuss in further detail.

\subsubsection{Potentiometry}

A frequently used electrochemical technique in an ion-sensitive device is potentiometry, which measures the voltage difference between two electrodes. Potentiometric ionsensitive sensors are based on an ion-sensitive membrane or ion-selective electrode (ISE). For example, ion-selective field effect transistors (ISFET) function when the ion-sensitive membrane adsorbs target analytes. Based on the various concentrations, the potential of the ionized membrane will change once the analyte is attached on the surface of the film. Consequently, the potential will drive the device to conduct electrical signals for ionic detection. This potentiometric technique has been used routinely for the testing of key electrolytes in physiology and chemistry [66]. Many techniques have been used to monitor $\mathrm{Fe}^{3+}$ ions from different samples. Most of the proposed methods have complex procedures and there are few potentiometric sensors for $\mathrm{Fe}^{3+}$ ions detection based on porphyrins. Dana Vlascici et al. [67] proposed a potentiometric sensor for $\mathrm{Fe}^{3+}$ based on 5-(4-carboxyphenyl)-10,15,20-tris(4-phenoxyphenyl)-porphyrin that was plasticized with bis(2-ethylhexyl)sebacate. This work demonstrated a sensitivity slope of $21.6 \mathrm{mV} /$ decade, a linear range of $10^{-7}-10^{-1} \mathrm{M}$, and response time of $20 \mathrm{~s}$. The $\mathrm{pH}$ sensing range was from 2.0 to 3.8 and also showed good selectivity toward cations.

Tao Liang et al. [68] also established a program-controlled multiplexed system for the detection of physiological ions such as $\mathrm{Na}^{+}, \mathrm{K}^{+}$and $\mathrm{H}^{+}$by combining potentiometric sensors with a variety of ion-selective membranes (ISMs). The commonly used ISMs have many disadvantages, such as poor adhesion to silicone-based sensors. The siliconerubber ISMs have better adhesion to silicone-based sensors. The proposed programcontrolled multiplexed system has good selectivity and long-term stability. Moreover, this system has good sensitivity with micro-molar limit of detection, which is well sufficient for the detection of ions in human biofluid, such as $\mathrm{Na}^{+}$and $\mathrm{K}^{+}$in human sweat (mM concentration range).

Based on the potentiometric measurements of cations $\left(\mathrm{K}^{+}, \mathrm{Ca}^{2+}\right.$, and $\left.\mathrm{Na}^{+}\right)$, Marek Dębosz et al. [69] constructed 3D-printed solid-contact ion-selective electrodes, where multiple ion electrodes with ion-selective membranes were integrated into one flow module for multicomponent water analysis. Several potentiometric detectors for physiological ions were introduced [70]. They showed interesting work of potentiometric sensors for ions that were developed with microneedles. In particular, acupuncture needles are considered as an ideal tool to develop microelectrodes for in vivo sensing. Jiali Zhai et al. [71] achieved a microsensor that allows in vivo monitoring of $\mathrm{Ca}^{2+}$ in cerebrospinal fluid via an acupuncture needle. In this work, an ion-selective microelectrode (IS $\mu \mathrm{E})$ has been developed by coating an acupuncture needle tip (diameter about $80 \mu \mathrm{m}$ ) with poly(3,4-ethylenedioxythiophene)poly(sodium 4-styrenesulfonate) as solid contact. The detection limit of the proposed $\mathrm{Ca}^{2+}$-IS $\mu \mathrm{E}$ is $1.2 \times 10^{-7} \mathrm{M}$, and the sensing slope is $30.8 \pm 0.9 \mathrm{mV} /$ decade in the range from $1.0 \times 10^{-6}$ to $3.1 \times 10^{-3} \mathrm{M}$.

\subsubsection{Cyclic Voltammetry}

Cyclic voltammetry (CV) is a method of electrochemical measurement. During a $\mathrm{CV}$ measurement, the potential of the working electrode is linearly ramped with time. When the potential has reached a designated level, the potential of the working electrode 
is ramped in the opposite direction to return to the default potential. This cycle may be repeated multiple times. A cyclic voltammogram can then be plotted by tracing the current versus the applied voltage at the working electrode. Currently, voltametric techniques are applied frequently to determine pollutants because of their low cost, simple operations, high sensitivity, and fewer requirements for reagents [72].

Many works have been proposed using CV method. Li-Da Chen et al. [73] developed simple electrochemical electrodes to detect sodium, chloride, and potassium ions in human serum. In this method, a gold-film thin electrode was used as the detection electrode for chloride ions and a solid-state ion-selective electrode was developed for the detection of sodium and potassium ions. The detection data can be obtained through cyclic voltammetry and square-wave voltammetry, and the ranges of detection were 2-10, 25-200, and 50-200 mM for the standard sample of potassium, chloride, and sodium, respectively.

Jiyang Wang et al. [74] also proposed a novel electrochemical sensor that was based on electropolymerized ion imprinted poly(o-phenylenediamine) PoPD/electrochemical reduced graphene oxide (ERGO) composite for determining trace $\mathrm{Cd}^{2+}$ on glassy carbon electrode in water. In this process, ERGO was deposited through cyclic voltammetry on the surface of the glass carbon electrode to enhance the transport of electron activity at the surface of the electrode. Through cyclic and square-wave voltammetry, the electrochemical behavior of PoPD/ERGO/GCE was investigated. This fabricated sensor has shown good selectivity toward target $\mathrm{Cd}^{2+}$ ions in the presence of other heavy metal ions and was successfully applied in a real water sample for the determination of trace $\mathrm{Cd}^{2+}$.

Hamsawahini Kunashegaran et al. [75] discussed both cyclic voltammetry and square wave voltammetry methods for $\mathrm{Pb}^{2+}$ quantification. This study used graphite reinforced carbon (GRC) as a substrate material and the electrode was modified with graphene oxide for electrochemical reduction to selectively detect $\mathrm{Pb}^{2+}$ ions. The result shows highly conductive GRC that expedites the reduction in graphene oxide and $\mathrm{Pb}^{2+}$ ions to enhance the detection of $\mathrm{Pb}^{2+}$ ions.

\subsubsection{Stripping Voltammetry}

There are many recent papers related to the stripping voltammetric determination of ions [76-78]. The basic operating principle of square wave anodic stripping voltammetry (SWASV) is to give a large amplitude square wave potential to the working electrode and collect the reaction current through the square wave cycle. SWASV is one of the most effective methods for measuring trace metals concentration. Compared with the traditional voltammetry method, it has higher sensitivity and lower detection limits [79]. Using SWASV, Chandre M. Willemse et al. [80] investigated a Nafion-Graphene nanocomposite in combination with in situ mercury film for the simultaneous detection of cations, such as $\mathrm{Zn}^{2+}, \mathrm{Cd}^{2+}$, and $\mathrm{Pb}^{2+}$. The detection limit obtained for each metal was $\mathrm{Zn}^{2+}\left(0.07 \mu \mathrm{g} \cdot \mathrm{L}^{-1}\right)$, $\mathrm{Cd}^{2+}\left(0.08 \mu \mathrm{g} \cdot \mathrm{L}^{-1}\right)$, and $\mathrm{Pb}^{2+}\left(0.07 \mu \mathrm{g} \cdot \mathrm{L}^{-1}\right)$. This technique could satisfy the requirements of the Environmental Protection Agency (EPA) and establish a highly enhanced sensing platform [80].

In biofluids, homeostasis of ionized calcium is critical for human organ systems and biological functions. However, it is not easy to measure ionized calcium for clinical applications, since the verification procedure is complicated and dependent on the $\mathrm{pH}$ level. Hnin Yin Yin Nyein et al. [81] described a highly selective, repeatable, flexible, and wearable microsensor array to monitor human body fluids. The device can perform multiplexed measurements of the concentrations of $\mathrm{Ca}^{2+}$ and $\mathrm{pH}$. By interfacing with a flexible printed circuit board, the device takes a sensor's calibration and compensation into account. For instance, a temperature sensor is integrated into the device for skin temperature measurement and calibration purposes.

To summarize our discussion up to this point, Table 1 shows a list of detection scenarios according to the detection technique, device type, electrode type, and targeted analytes for comparison. 
Table 1. Various electrochemical devices for ionic analytes.

\begin{tabular}{|c|c|c|c|c|}
\hline Detection Technique & Device & Electrode & Analytes & Ref. \\
\hline \multirow{8}{*}{ Potentiometric } & Ion-sensitive field-effect transistor & $\mathrm{ZnO}$ nanorod & $\mathrm{PO}_{4}{ }^{3-}, \mathrm{NO}_{3}{ }^{-}, \mathrm{K}^{+}$ & [47] \\
\hline & Ion-selective sensor & Screen-printed electrode & $\mathrm{F}^{-}$ & [42] \\
\hline & Ion-selective sensor & Screen-printed electrode & $\mathrm{Cl}^{-}$ & [63] \\
\hline & Ion-sensitive field effect transistors & Graphene electrode & $\mathrm{K}^{+}$ & [35] \\
\hline & Ion-selective sensor & Screen-printed electrode & $\mathrm{K}^{+}, \mathrm{NH}_{4}^{+}$ & [64] \\
\hline & Ion-selective sensor & Silver electrode & $\mathrm{Ag}^{+}$ & [48] \\
\hline & Ion-selective sensor & Chromium/gold electrode & $\mathrm{K}^{+}, \mathrm{Na}^{+}$ & [82] \\
\hline & Ion-selective sensor with gold nanodendrites & Gold/electrode & $\mathrm{Na}^{+}, \mathrm{K}^{+}$ & [25] \\
\hline \multirow{3}{*}{ Voltammetric } & Nanoparticles/nanosheets-modified sensor & Carbon paste electrode & $\mathrm{Cu}^{2+}, \mathrm{Pb}^{2+}, \mathrm{Bi}^{3+}$ & [76] \\
\hline & Nitrogen-doped reduced graphene oxide modified sensor & Glassy carbon electrode & $\mathrm{Hg}^{2+}$ & [78] \\
\hline & Nafion-graphene nanocomposite sensor & Glassy carbon electrode & $\mathrm{Zn}^{2+}, \mathrm{Cd}^{2+}, \mathrm{Pb}^{2+}$ & [80] \\
\hline
\end{tabular}

\section{Applications of Ion-Selective Devices}

\subsection{Health Sensors}

Biofluids such as blood, sweat, urine, and tears contain rich physiological information $[9,41,45,81,82]$. In recent years, there are extensive studies on sweat sensing, which has the advantage of non-invasive monitoring. Traditionally, hospitals have been using sweat to screen newborns with cystic fibrosis by monitoring the balance between sodium and chlorine in sweat [45]. Since it is challenging to capture and analyze human sweat in real time with a bulky system, wearable ionic sensor technologies can play a significant role to address this problem. These technologies can simultaneously, continuously, and conveniently monitor a person's health in real time $[45,82]$. In a wearable device, a wearer's motion will be less restricted compared to a conventional bulkier instrument during a measurement. Some wearable devices have been developed to alert athletes about imbalances in their electrolyte levels, which may indicate excessive exercise or dehydration [49].

One benefit of sweat monitoring technology is that the procedure can be completely non-invasive. Therefore, the subjects do not need to perform finger pricking to obtain access to biomarkers. Wei Gao et al. [82] merged a plastic-based sensors array with biosignal processors to perform wireless transmission of data measured from perspiration. Figure 3A shows a flexible integrated sensing array (FISA) that can achieve long-term monitoring of electrolytes $\left(\mathrm{K}^{+}, \mathrm{Na}^{+}\right)$, metabolites (glucose, lactate), and skin temperature during physical activities. The fabricated sensors are integrated on flexible PET substrate with the advantage of being flexible and conformal to the skin. After packaging as FISAs, smart "headbands" and "wristbands" are worn for simultaneous real-time monitoring during physical motion on an ergometer. Figure 3B shows multiplexed sensor array for sweat analysis. The $\mathrm{Ag} / \mathrm{AgCl}$ electrode is fabricated to serve as a shared counter electrode and reference electrode. Ion-selective electrodes (ISEs) are fabricated with a polyvinyl butyral (PVB) coated reference electrode to maintain a stable measurement state with different ionic strength levels of $\mathrm{Na}^{+}$and $\mathrm{K}^{+}$. For functionalizing as a potentiometric sensor, poly(3,4-ethylenedioxythiophene) polystyrene sulfonate (PEDOT:PSS) is chosen as an ionelectron transducer for $\mathrm{Na}^{+}$and $\mathrm{K}^{+}$ions in the ISEs. $\mathrm{Cr} / \mathrm{Au}$ metal microwires are fabricated as resistive temperature sensors. Parylene coating is applied to prevent electrical contact between the metal lines and the skin. The stability of the sensor's reading is displayed on a customized mobile app in Figure 3C.

Health sensors can also be inserted into a subject's mouth for the measurement of food intake to control eating behavior that can be related to diseases such as hypertension, severe obesity, and diabetes. Yongkuk Lee et al. [83] proposed a wireless intraoral electronic system that quantified the sodium intake for hypertension management in real time. The major objective of this system was to achieve active and long-range wireless communication. This was offered by hybrid electronics to overcome the limitations of near field telemetry that allowed communication within a few centimeters of distance. Figure 3D shows a membranous device with an integrated circuit incorporated on a contoured dental holder for easy handling and non-invasive insertion into the mouth. Any portable and Bluetooth connected devices, including smartphones, can connect easily with electronics 
for the management of diet through real time food intake monitoring. The small form of the membrane electronics is captured by X-ray microtomography (Bruker, Billerica, Massachusetts, USA). Figure 3E shows electronics laminated on a custom porous retainer surface. Figure 3F shows an experimental result of the selectivity of the sodium sensor. For the detection of sodium intake, the ISE selectivity is sufficient for practical scenarios where a typical type of food may contain interfering $\mathrm{K}^{+}, \mathrm{Ca}^{2+}$, and $\mathrm{Mg}^{2+}$ ions.

\subsection{Integrate with Gloves for Human Fluid}

Sensing gloves can be integrated onto a wearable platform [84]. Similarly, the idea of sensing analytes at the fingertip has been demonstrated, such as the electrochemical on-site screening of cocaine [85], solid-state forensic finger sensor for the detection of gunshot residue and explosives [86], and the detection of organophosphorus chemical threats [87]. Several types of sweat sensors have been developed to non-invasively and continuously obtain access to biofluids. Mallika Bariya et al. [88] proposed a functional glove-based sensor which can accumulate natural sweat with minimal evaporation. This sensor collects microliters of sweat without active sweat stimulation. In this system, the sensing electrodes were patterned on nitrile gloves and finger cots for in situ detection of diverse biomarkers, including electrolytes and xenobiotics. These electrodes were fabricated in various patterns and deposited on the inner surfaces of nitrile gloves or finger cots. The electrode areas are defined by a shadow mask and formed through evaporating conductive materials. Gold and bismuth electrodes are also coated on glove surface and in contact with the back of the hand that has high sweat rate. Through the direct integration of sensors into gloves, the authors presented a simple and lower overhead scheme for natural sweat analysis, which enabled a more practical approach without the need for highly complex components to monitor multiple analytes. Figure $3 \mathrm{G}$ shows a schematic of analyzing human sweat through glove-based analytics without active sweat stimulation. The glovebased sensors including the functionalized cots allow sweat analysis during routine and sedentary activities. Figure $3 \mathrm{H}$ illustrates the concept of allowing electrochemical sensors patterned on glove surfaces (including backside). In this work, the sensors are placed around areas of the hand where sweat rates are high. Figure 3I shows nitrile as a key material for sweat functionalized finger cots, which can be worn on gland-rich fingertips while offering a compacted form factor.

\subsection{Agriculture and Produce}

The quantity and variety of food have dramatically increased the need for sensors for the food industry. Food safety holds a significant impact on human health, economy, and consumers' experience [89-91]. Therefore, the requirement for food quality monitoring has increased considerably and harmful chemicals such as heavy metals are important targets. Jing Wang et al. [92] implemented a method based on solid phase detection of $\mathrm{Pb}^{2+}$ in food and water samples. The developed device has been synthesized by nanosheets alginate hydrogel based on layered double hydroxides (LDHs) with the hydrogel having the advantages of porous 3D framework and selective adsorption of LDHs to $\mathrm{Pb}^{2+}$.

The development of smart agricultural control systems has been a trend in recent years $[18,93]$. Advanced smart devices enable accurate control of a plant's growing environment. The crops' growth can be recorded and analyzed in real time and, in turn, effectively reduce the costs to improve the crops' yield and quality [94]. In another work, polyvinyl chloride membrane-based dibasic phosphate $\left(\mathrm{HPO}_{4}{ }^{2-}\right)$ ion-selective electrodes doped with urea- and thiourea-calix[4]arene ionophores have been demonstrated with good sensitivity with near-Nernstian slope in the concentration range of $5.0 \times 10^{-5}$ to $1.0 \times 10^{-1} \mathrm{M}$ of $\mathrm{HPO}_{4}{ }^{2-}$ [95]. One key component for developing smart agriculture is to implement ionic sensors, which can monitor nitride and phosphorous effectively to help control the growth of the crops. Huawei Jiang et al. [96] reported a microfluidic chip with integrated nutrient $\left(\mathrm{H}_{2} \mathrm{PO}_{4}{ }^{-}\right.$and $\left.\mathrm{NO}_{3}{ }^{-}\right)$sensors for nitrate and phosphorous monitoring for plants grown under known growth medium. The embedded nutrient sensors detect the concentrations of 
the targeted ions in the medium as the root uptakes the nutrients. To note, $2.14 \times 10^{-6}$ and $1.78 \times 10^{-6} \mathrm{~mol} / \mathrm{L}$ are the detection limits for $\mathrm{H}_{2} \mathrm{PO}_{4}{ }^{-}$and $\mathrm{NO}_{3}{ }^{-}$, while the sensitivities for $\mathrm{H}_{2} \mathrm{PO}_{4}{ }^{-}$and $\mathrm{NO}_{3}{ }^{-}$are $-55.7 \pm 2.9$ and $-58.6 \pm 1.7 \mathrm{mV} / \mathrm{dec}$, respectively. This sensing chip demonstrates real-time monitoring of the plants' nutrient uptake efficiency.

For soil quality monitoring, laser induced graphene (LIG) is one technology that promises an alternative to ink-based technology [97,98]. Nate T. Garland et al. [99] demonstrated a sensor for $\mathrm{NO}_{3}{ }^{-}$and $\mathrm{NH}_{4}{ }^{+}$through a low-cost and one-step UV laser writing fabrication method. Figure 3J shows solid contact ion-selective electrodes (SC-ISEs) on a single polyimide swatch, which is written with different laser pulse widths (10, 20, 30, 40, and $50 \mathrm{~ms}$ ) to optimize the LIG electrochemical reactivity. Figure $3 \mathrm{~K}$ shows representative electrodes (passivated regions, bonding pads, working electrode, and reference electrode) used in soil column studies. Figure 3L illustrates the SC-ISEs ion sensing result.

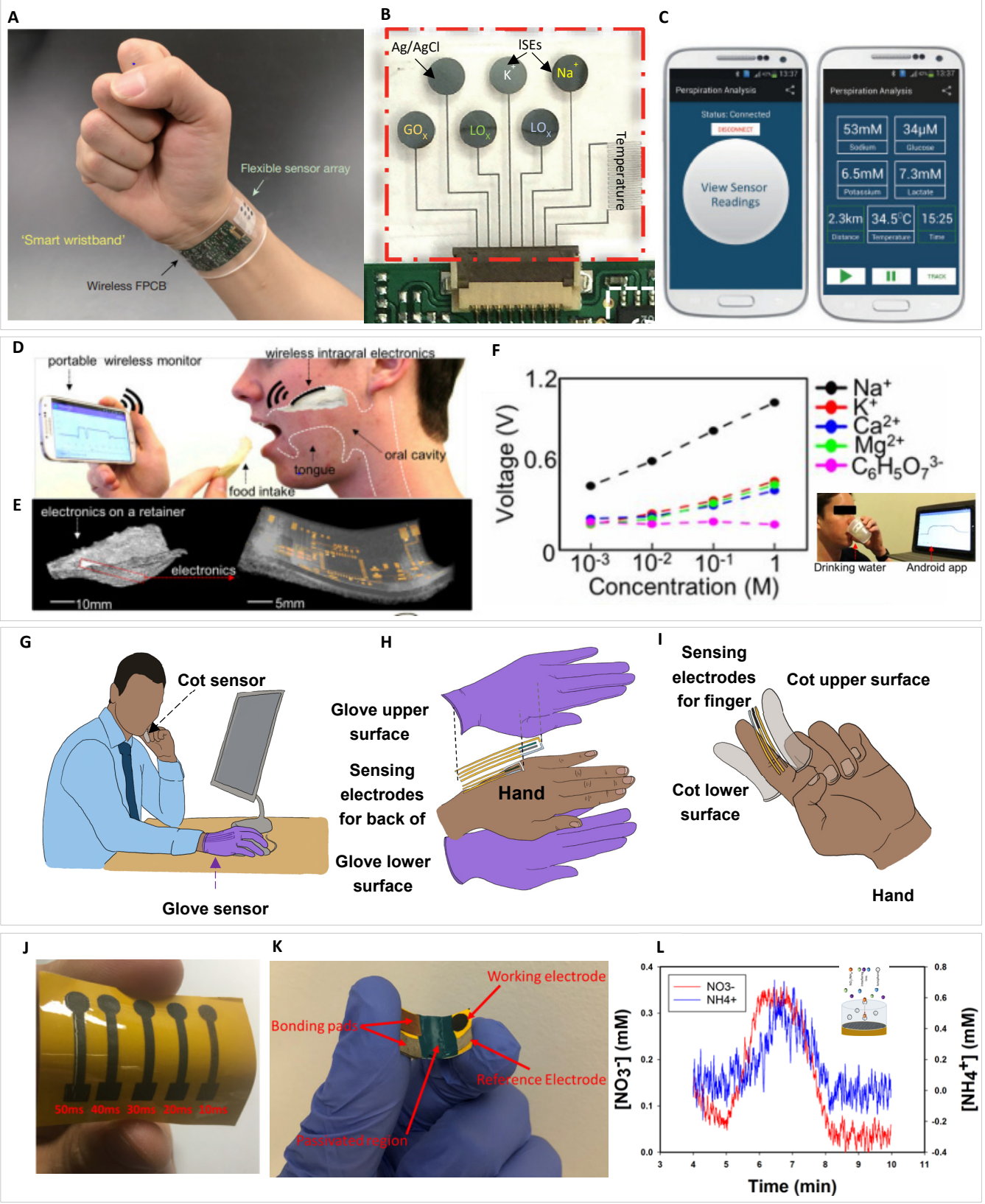

Figure 3. Wearable sweat sensor and ion sensing results via wireless Bluetooth transmission on a mobile device. (A) Shows the wireless flexible printed circuit board (FPCB) and integrated multiplexed sweat sensor array and of a wearable flexible integrated sensing array (FISA) on a subject's wrist. (B) Multiplexed sensor array for sweat analysis. The red dashed box shows the sensor array. 
(C) A mobile application for real-time data display. (A-C) Reproduced with permission. Copyright 2016, Nature Publishing Group [82]. (D) Overview of real-time monitoring of sodium intake with intraoral electronics. (E) Images of an ultrathin intraoral device; the left figure shows electronics laminated conformably on an oral retainer and the right figure shows circuit interconnects on a porous membrane. (F) Sensing results in the presence of $\mathrm{Na}^{+}, \mathrm{K}^{+}, \mathrm{Ca}^{2+}, \mathrm{Mg}^{2+}$, and citric acid. The figure shows the amplitude output of the sodium sensor. The inset part shows in vivo testing setup with a human subject drinking the sodium solution. (D-F) Reproduced with permission. Copyright 2019, American Chemical Society [83]. (G-I) Natural sweat analysis with glove-based analytics. (G) Shows functionalized gloves and cots, which are included in glove-based sensors for natural sweat analysis during routine activity and sedentary without active sweat stimulation. (H) Illustrates the concept of allowing electrochemical sensors patterned on glove surfaces. For rapid sweat accumulation, nitrile is a crucial material of the glove to protect against evaporation. (I) Functionalized electrodes inside finger cots for sweat analysis. The nitrile cots can offer a condensed form factor that can be functionalized to detect sweat from gland-rich fingertips. Reproduced with permission. Copyright 2020, American Association for the Advancement of Science [88]. (J) Laser induced graphene (LIG) structure and functionalization for ion-selective sensing. Solid contact ion-selective electrodes (SCISEs) are patterned on a single polyimide swatch. (K) Shows representative electrodes used in soil column studies. (L) Illustrates the SC-ISEs' ion sensing result. (J-L) Reproduced with permission. Copyright 2020, American Chemical Society [99].

\subsection{Environmental and Water Quality Sensors}

The problem of heavy metal ion pollution in water in the environment is becoming more common nowadays. Pengju Wei et al. [100] developed a surface ion-imprinting polymer (IIP) copper ions sensor based on a glassy carbon electrode $\left(\mathrm{Fe}_{3} \mathrm{O}_{4} / \mathrm{SiO}_{2} / \mathrm{CS} / \mathrm{Nafion} / \mathrm{GCE}\right)$. Through the differential pulse anodic stripping voltammetry (DPASV), the proposed sensors show high selectivity for monitoring copper ions when there are coexisting, interfering metal ions ( $\mathrm{Cr}$ (VI), Fe (II), etc.). $\mathrm{Fe}_{3} \mathrm{O}_{4} / \mathrm{SiO}_{2} / \mathrm{CS} / \mathrm{Nafion} / \mathrm{GCE}$ IIP based sensors not only have good repeatability but also a wide linear detection range $\left(0.01 \sim 20 \mu \mathrm{mol} \mathrm{L}^{-1}\right)$ and low detection limit $\left(5 \mathrm{nmol} \mathrm{L}{ }^{-1}\right)$. The detection of arsenic that can seriously endanger human health is also an important concern. Haibing Hu et al. [101] used a glassy carbon electrode with uniformly modified $\mathrm{Fe}_{3} \mathrm{O}_{4}-\mathrm{rGO} 20$-nm nanoparticles for arsenic detection, where reduced graphene oxide (rGO) serves as a conductive sheet with high sensitivity. The result shows a lower limit of detection (1.19 ppb) and higher sensitivity $(2.15 \mu \mathrm{A} / \mathrm{ppb})$ for arsenic in the water through square wave voltammetry.

Most of the pollution sources are caused by human activities when industrial waste exceeds the self-purification capacity of the environment [102]. This situation can harm the natural ecological system of the environment as well as human health. To overcome this problem, new technologies and procedures to monitor the contamination levels in the polluted environment are essential. Sona Krizkova et al. [103] successfully presented an ultrasensitive detection with carbon paste electrodes to detect silver ions, with $0.5 \mu \mathrm{M}$ as the estimated detection limit ( $3 \mathrm{~dB} /$ Noise ratio). Megha A. Deshmukh et al. [26] discussed the use of organic conducting polymers and carbon nanotubes to enhance the sensitivity and selectivity of heavy metal detections. Because of the unique electrical, chemical, mechanical, and structural properties of those materials, they have been adopted in the detection of trace metals, such as $\mathrm{Pb}^{2+}, \mathrm{Cu}^{2+}, \mathrm{Cd}^{2+}, \mathrm{Zn}^{2+}, \mathrm{Hg}^{2+}, \mathrm{Cr}^{2+}, \mathrm{Ni}^{2+}$, and $\mathrm{Co}^{2+}$.

\section{Integration of Electrochemical Sensors for Ionic Analytes and Energy Harvesting Electronics}

Electrochemical sensors for ionic analytes are powerful devices because of their portability. With the development of various mobile electronics, technology that is capable of supplying a battery in environments where it is not possible to provide a stable power supply is essential. In this regard, energy harvesting has attracted attention and energy harvester shows a viable method to overcome the limitation of battery capacity that can 
constrain the long-term operation of implantable and wearable devices [104-108]. These energy harvesting sensors are self-powered from the ambiance, and the converted electric power can be applied in the sensing process instantly. They do not need an extra power source, time-consuming charging duration, and complex procedures for sensing. Therefore, energy harvesting is an attractive functionality to include with a wearable device for ionic analytes [104,108]. A self-powered device will be advantageous to those who need continuous monitoring for fitness management and health monitoring. In the following section, we are going to introduce several mechanisms of self-powered energy harvesters integrated with an electrochemical device for ionic sensing.

\subsection{Triboelectric-Powered Energy Harvester for Electrochemical Ionic Sensing}

Despite much research on wearable energy harvesters, most of them suffer from poor robustness, complex fabrication process, and low power density. The above issues make them inconvenient for continuous monitoring. In triboelectric-powered energy, triboelectric is a static electricity on which certain materials become electrically charged after they are separated from the original material with which they were in contact. This is an effective energy harvesting technique, which provides necessary power for small electronics.

In order to generate a sustainable and energy-efficient wearable device, Yu Song et al. [104] proposed a wearable freestanding triboelectric nanogenerator (FTENG) energy harvester based on a flexible printed circuit board. This device efficiently allows the collection of power from human motion with battery-free, robust, and mass-producible properties. The engineered FTENG demonstrates a triboelectric and battery-free system to power multiplexed sweat sensing and wireless data transmission during on-body human exercise trials. In this work, sensitivities are measured with physiologically relevant $\mathrm{Na}^{+}$concentrations (12.5 to $200 \mathrm{mM}$ ) and $\mathrm{pH}$ levels (4 to 8). Sensitivities of $\mathrm{Na}^{+}$and $\mathrm{H}^{+}$are 58.63 and $56.28 \mathrm{mV}$ per decade concentration, respectively. The result is close to Nernstian sensitivities and high sensing performance is proven. Figure $4 \mathrm{~A}$ shows a battery-free FTENG-powered wearable sweat sensor system $\left(\mathrm{FWS}^{3}\right)$ for wireless and non-invasive sweat monitoring. The left side shows integrated human motion energy harvesting $\mathrm{FWS}^{3}$, which has power supply to Bluetooth-based wireless data transmission in real-time for health status monitoring. This device includes a mobile user interface and microfluidic-based sweat sensing functionality. The right side shows different working frequencies of FTENG and its current output during the energy harvesting process.

\subsection{Biofuel-Powered Energy Harvester for Electrochemical Ionic Sensing}

Due to interests in alternative fuels in the past few years, biofuel cells have become an important topic of research [105-108]. This presents a unique opportunity to integrate with electrochemical sensors for ionic sensing. A fuel cell is an electrochemical cell that can generate current from reactions between the chemical species flowing into the cell [105]. When biofuel cells can be a power source for ionic-sensing wearable sensors, it provides a way for long-term biosensing on a standalone platform, where the energy generated from sweat can be used in ionic sensing [106].

Hee Uk Lee et al. [107] developed a graphite oxide/cobalt, hydroxide/chitosan composite material, which has high specific surface area and redox activity, and the maximum power density is $517 \mu \mathrm{W} \cdot \mathrm{cm}^{-2}$. You Yu et al. [108] presented a biofuel-powered energy harvester on skin sensing platforms. Many existing sensing platforms of electronic skin rely on batteries or near-field communication for power charging, which is inconvenient and restricted by the locations of the wireless equipment. This work overcame the above limitation and demonstrated a battery free biomedical device with fully perspiration-powered electronic skin (PPES). The key metabolic biomarkers such as $\mathrm{NH}_{4}{ }^{+}$, glucose, urea, and $\mathrm{pH}$ are monitored and transmitted wirelessly in a continuous way to a mobile device via Bluetooth low energy (BLE). Figure 4B shows photographs of a PPES on a testing subject's arm, a reference sensing electrode, and an ion sensor on a flexible BFC-biosensor patch. The potentiometric response of the $\mathrm{NH}_{4}{ }^{+}$is measured under 2.5 to $40 \mathrm{mM} \mathrm{NH}_{4}{ }^{+}$solutions. The 
outcome shows a linear potential output versus logarithmic concentrations of the target analyte, with near-Nernstian sensitivities of $60.3 \mathrm{mV}$ per decade of concentration for $\mathrm{NH}_{4}^{+}$ sensors. This work demonstrates PPES that harvests energy from human lactate biofuel cells through human sweat.

\subsection{Photovoltaic-and Thermoelectric-Powered Energy Harvester for Electrochemical Ionic Sensing}

Solar energy is one kind of renewable energy source, with its promise to supply a share of the global energy demand $[109,110]$. In particular, photovoltaic (PV) devices are used to generate electrical power via semiconductors that exhibit photovoltaic effects to convert solar radiation into direct current. Several PV technologies, such as perovskite solar cells and dye-sensitized solar cells (DSSC), were reported. PV have high potential for mass production with manufacturing methods such as screen printing, inkjet printing, or slot-die coating to produce electrochemical sensors for ions [111-114]. In prior demonstrations of the concept, a dye-sensitized solar cell is used for both sensitive detection and power generation of ionic analytes, which kick off a new pathway for integration and ultraminiaturization. Since its beginning, dye-sensitized solar cell technology has proven stability and simplicity of fabrication while being able to sustain competitive efficiencies of power conversion [115].

A versatile detection strategy was demonstrated by Kanika L. Agrawala and Max Shtein [116]. The proposed device of this work was for sensing, and the power generation was achieved using a single DSSC device. A DSSC is responsive to the occurrence of ionic species, such as silver, and that generates a change in its electrical characteristics. When introducing silver ions into the electrolyte of a general operating DSSC, the Ag ions will be adsorbed, and the metal will be deposited on the mesoporous $\mathrm{TiO}_{2}$ electrode. Then, it reduces the driving level for charge injection while the deposited metals can make dye sites inactive and halt the recombination between electrons. This approach can reliably detect microscale concentrations of charged species in solutions without making substantial adjustments to a well-understood photo-electrochemical system. The DSSC technology for autonomous sensing of metal ion pollution in environments with high sensitivity and repeatability can pave the path for new applications. Figure $4 \mathrm{C}$ shows dye-sensitized photovoltaic cell and the response of the presence of ionic species that produces a change in its electrical features. The Ag ions are introduced into the electrolyte of a DSSC under operation mode, and the adsorption of $\mathrm{Ag}$ ions form metallic precipitations on the $\mathrm{TiO}_{2}$ electrode. Figure 4D shows the method for testing the sensor through injecting electrolytes.

Thermoelectric (TE) devices have received attention since they are able to convert temperature gradients into electricity. They possess the potential to become a candidate that allows for the operation of self-powered sensors that are separated from a localized power supply [117,118]. Yu-HsiangTsao et al. [119] showed that the mechanism of thermoelectric generators can be implemented to design a modern prototype of a self-powered sensor for the detection of $\mathrm{Hg}^{2+}$ ions. Generally, the performance of thermoelectric generators depends on the critical thermoelectric materials, which is the key factor to determine the sensing capability of the thermoelectric sensor. For the past few years, nanostructures of tellurium have been proven to be highly efficient thermoelectric materials. Tellurium shows novel properties and has the ability to be applied in piezoelectric nanogenerators [120,121]. Here, tellurium nanowires (Te NWs) were selected as the essential material for the self-powered thermoelectric sensor. Their excellent thermoelectric performance property comes from $\mathrm{HgTe}$ nanocrystals, where the specific reaction of $\mathrm{Hg}^{2+}$ ions and $\mathrm{Te} \mathrm{NWs}$ leads to higher thermoelectric efficiency. The as-constructed thermoelectric sensor has high selectivity and sensitivity (detection limit of $1.7 \mathrm{nM}$ ) for $\mathrm{Hg}^{2+}$ ion.

The proposed thermoelectric sensor can supply an intense electric output signal even when it is driven by a small temperature difference. Figure 4E shows the structure of the self-powered thermoelectric nanosensor and its sensing process for the detection of mercury ions vs. different metal ions. Figure $4 \mathrm{~F}$ shows the output measurement of multiple ions. After 30 min of reaction time, PEDOT:PSS is coated on the wells to finalize the 
fabrication of thermoelectric nanosensors. Finally, electrical signal can be outputted across the thermoelectric nanosensors.
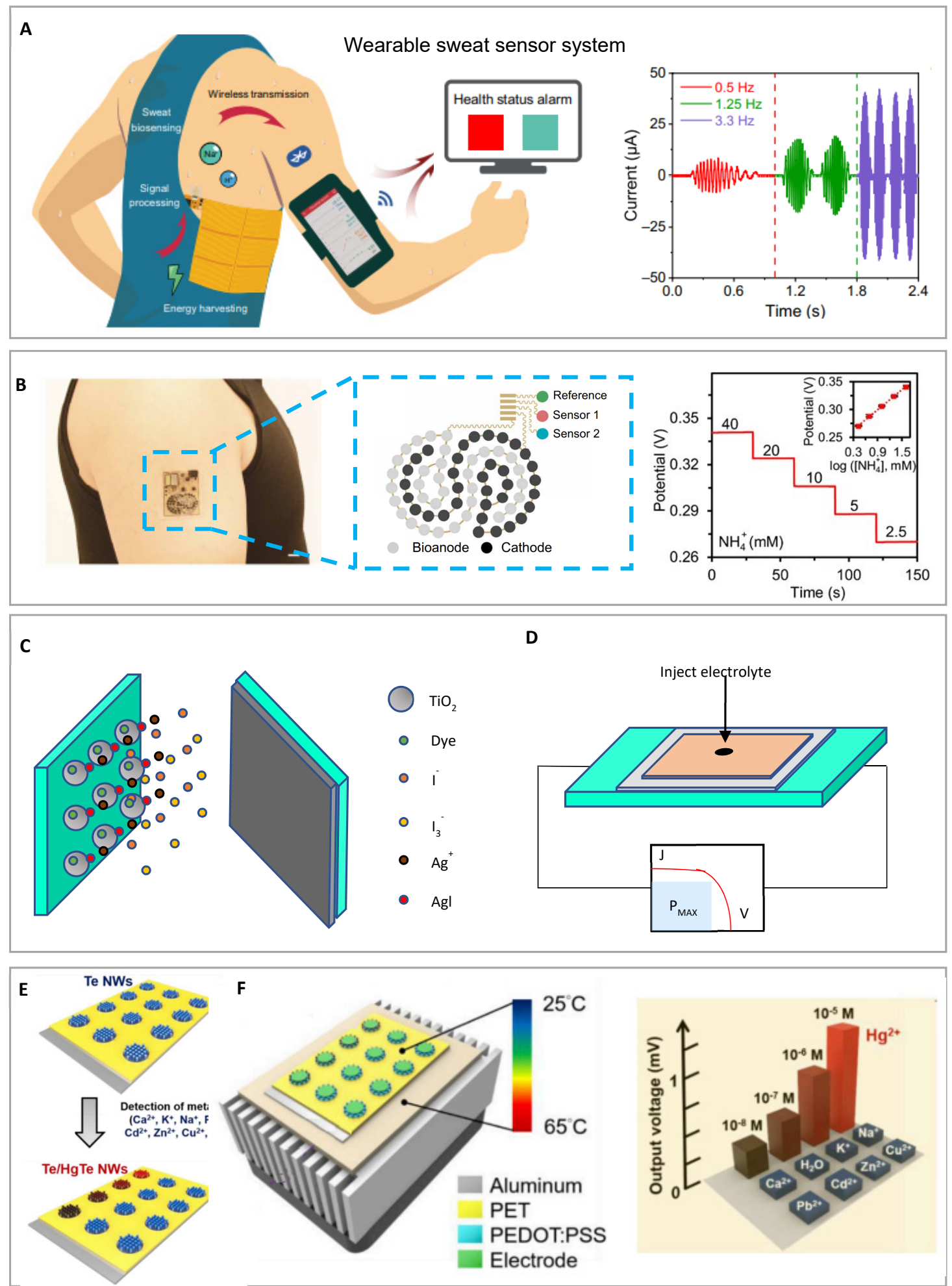

Figure 4. (A) From left to right shows integrated human motion energy harvesting a freestanding triboelectric nanogenerator (FTENG)-powered wearable sweat sensor system and the output energy. Reproduced with permission. Copyright 2020, American Association for the Advancement of Science [104]. (B) From left to right shows a biofuel-powered energy harvester and its output energy. The potentiometric responses of the $\mathrm{NH}^{4+}$ sensors are measured in 40 to $2.5 \mathrm{mM} \mathrm{NH}^{4+}$ solutions and they demonstrate near-Nernstian sensitivities of $60.3 \mathrm{mV}$ per decade of concentration. Reproduced 
with permission. Copyright 2020, American Association for the Advancement of Science [108]. (C) Shows dye-sensitized solar cell (DSSC), which will produce a change with its electrical characteristics in response to the ionic species, while introducing Ag ions into the electrolyte of a DSSC results in the adsorption of $\mathrm{Ag}$ ions as well as the formation of metallic precipitation on the mesoporous $\mathrm{TiO}_{2}$ electrode. (D) Shows a representation of the testing procedure. The devices were connected to a Solartron Analytical Modulab test system. The impedance spectra and electrical characteristics were measured under 1 sun illumination and in the dark. (C,D) Reproduced with permission. Copyright 2014, Royal Society of Chemistry [116]. (E) Shows self-powered thermoelectric nanosensor and sensing process for $\mathrm{Hg}^{2+}$ detection. Tellurium nanowires (Te NWs) here acted as a thermoelectric material as well as a sensor. (F) The electrolyte is sucked into the vacuum cavity, and its sensing process for mercury ions are reported after electrochemical reaction. Finally, the electric output was performed by using Peltier system to create a temperature gradient across the thermoelectric nanosensors. (E,F) Reproduced with permission. Copyright 2019, Elsevier [119].

\section{Conclusions}

Chemical sensors for ionic analytes are involved in many different technologies. It has become ubiquitous and widely used, whether in the areas of environmental monitoring, biological research, food safety, healthcare, or drug optimization. In recent years, due to the rise of wearable devices and smart mobiles, they have the potential of being integrated into our daily life. Most wearable sensors on the market do not rely on direct chemical reactions with biomolecules but depend on spectral reflectance or absorption to obtain biomedical data. In this paper, we reviewed a wide variety of applications of ion-selective sensing devices. The technology in this field is quickly developing, and wearable devices can be used in a wide range of applications such as 3C mobile devices, sports fitness monitoring, and healthcare.

One of the core prognostic technologies of biological sensors is biomarkers monitoring for the human body. Biological molecules and chemical substances can be detected by wearable biological sensing devices, where the sensors transduce biological signals into electronic circuits. Therefore, the biochemical molecules are transformed into information for health-related interpretation. Because of the variations between human subjects, it is essential to develop various types of ionic sensors to capture a comprehensive understanding of an individual's health status. For example, the heart rate and blood pressure levels alone are difficult to obtain accurate interpretations of a person's health condition. Hence, a device that can collect information regarding ionic targets in the human body becomes important.

On the other hand, the applications of sensing technology can expand beyond biosensing. Here, we reviewed the applications of ionic sensors in different contexts, such as environmental and food quality monitoring. We expect the field of ionic sensors to have great importance in the future. When electrochemical sensors are integrated with other smart devices, we envision that they can be combined with big data and artificial intelligence to provide pathways toward new, exciting opportunities.

Author Contributions: Conceptualization, S.-Y.F. and S.K.; resources, L.-C.T.; writing—original draft preparation, S.-Y.F. and S.K.; writing-review and editing, C.H.A. and B.Z.; visualization, S.-Y.F. and S.K.; supervision, L.-C.T.; funding acquisition, L.-C.T. All authors have read and agreed to the published version of the manuscript.

Funding: This research was funded by the Yushan Young Scholar Program, the Ministry of Education, Taiwan.

Informed Consent Statement: Not applicable.

Acknowledgments: This work was supported by the Institute of Electrical and Control Engineering and the Department of Electrical and Computer Engineering at National Yang Ming Chiao Tung University (NYCU). The authors acknowledge valuable feedback from Hnin Yin Yin Nyein of 
Stanford University's Department of Radiology. S.K. acknowledges supports by the Scholarship for Outstanding New Students Award from NYCU (2021).

Conflicts of Interest: The authors declare no conflict of interest.

\section{References}

1. Camargo, J.A.; Alonso, A. Ecological and toxicological effects of inorganic nitrogen pollution in aquatic ecosystems-A global assessment. Environ. Int. 2006, 32, 831-849. [CrossRef]

2. Gumpu, M.B.; Sethuraman, S.; Krishnan, U.M.; Rayappan, J.B.B. A review on detection of heavy metal ions in water-An electrochemical approach. Sens. Actuators B 2015, 213, 515-533. [CrossRef]

3. Florea, A.M.; Busselberg, D. Occurrence, use and potential toxic effects of metals and metal compounds. BioMetals 2006, 19, 419-427. [CrossRef] [PubMed]

4. World Health Organization. Guidelines for Drinking-Water Quality, 4th ed.; Available online: https://www.who.int/water_ sanitation_health/publications/2011/9789241548151_ch12.pdf (accessed on 8 August 2021).

5. Lemos, S.G.; Nogueira, A.R.A.; Torre-Neto, A.; Parra, A.; Alonso, J. Soil calcium and pH monitoring sensor system. J. Agric. Food Chem. 2007, 55, 4658-4663. [CrossRef] [PubMed]

6. Zeglio, E.; Eriksson, J.; Gabrielsson, R.; Solin, N.; Inganäs, O. Highly stable conjugated polyelectrolytes for water-based hybrid mode electrochemical transistors. Adv. Mater. 2017, 29, 1605787. [CrossRef] [PubMed]

7. Wang, Z.; Sun, X.; Li, C.; He, X.; Liu, G. On-site detection of heavy metals in agriculture land by a disposable sensor based virtual instrument. Comput. Electron. Agric. 2016, 123, 176-183. [CrossRef]

8. Cambra, C.; Sendra, S.; Lloret, J.; Lacuesta, R. Smart system for bicarbonate control in irrigation for hydroponic precision farming. Sensors 2018, 18, 1333. [CrossRef]

9. Bariya, M.; Shahpar, Z.; Park, H.; Sun, J.; Jung, Y.; Gao, W.; Nyein, H.Y.Y.; Liaw, T.S.; Tai, L.-C.; Ngo, Q.P.; et al. Roll-to-roll gravure printed electrochemical sensors for wearable and medical devices. ACS Nano 2018, 12, 6978-6987. [CrossRef] [PubMed]

10. Lee, W.; Koo, H.; Sun, J.; Noh, J.; Kwon, K.-S.; Yeom, C.; Choi, Y.; Chen, K.; Javey, A.; Cho, G. A fully roll-to-roll gravure-printed carbon nanotube-based active matrix for multi-touch sensors. Sci. Rep. 2015, 5, 17707. [CrossRef] [PubMed]

11. Silva, R.R.; Raymundo-Pereira, P.A.; Campos, A.M.; Wilson, D.; Otoni, C.G.; Barud, H.S.; Costa, C.A.R.; Domeneguetti, R.R.; Balogh, D.T.; Ribeiro, S.J.L.; et al. Microbial nanocellulose adherent to human skin used in electrochemical sensors to detect metal ions and biomarkers in sweat. Talanta 2020, 218, 121153. [CrossRef]

12. Nyein, H.Y.Y.; Bariya, M.; Kivimäki, L.; Uusitalo, S.; Liaw, T.S.; Jansson, E.; Ahn, C.H.; Hangasky, J.A.; Zhao, J.; Lin, Y.; et al. Regional and correlative sweat analysis using high-throughput microfluidic sensing patches toward decoding sweat. Sci. Adv. 2019, 5, eaaw9906. [CrossRef]

13. Liang, J.; Zheng, Y.; Liu, Z. Nanowire-based Cu electrode as electrochemical sensor for detection of nitrate in water. Sens. Actuators B 2016, 232, 336-344. [CrossRef]

14. Kelly, C.; Cruz-Romero, M.; Kerry, J.; Papkovsky, D. Stability and safety assessment of phosphorescent oxygen sensors for use in food packaging applications. Chemosensors 2018, 6, 38. [CrossRef]

15. Traiwatcharanon, P.; Siriwatcharapiboon, W.; Wongchoosuk, C. Electrochemical sodium ion sensor based on silver nanoparticles/graphene oxide nanocomposite for food application. Chemosensors 2020, 8, 58. [CrossRef]

16. Tan, E.L.; Ng, W.N.; Shao, R.; Pereles, B.D.; Ong, K.G. A wireless, passive sensor for quantifying packaged food quality. Sensors 2007, 7, 1747-1756. [CrossRef]

17. Choi, J.R.; Yong, K.W.; Choi, J.Y.; Cowie, A.C. Emerging Point-of-care Technologies for Food Safety Analysis. Sensors 2019, $19,817$. [CrossRef]

18. Tang, W.; Wu, J.; Ying, Y.; Liu, Y. Writing sensors on solid agricultural products for In Situ detection. Anal. Chem. 2015, 87, 10703-10707. [CrossRef] [PubMed]

19. Sun, M.; Gu, Y.; Pei, X.; Wang, J.; Liu, J.; Ma, C.; Bai, J.; Zhou, M. A flexible and wearable epidermal ethanol biofuel cell for on-body and real-time bioenergy harvesting from human sweat. Nano Energy 2021, 86, 106061. [CrossRef]

20. Sonner, Z.; Wilder, E.; Heikenfeld, J.; Kasting, G.; Beyette, F.; Swaile, D.; Sherman, F.; Joyce, J.; Hagen, J.; Kelley-Loughnane, N.; et al. The microfluidics of the eccrine sweat gland, including biomarker partitioning, transport, and biosensing implications. Biomicrofluidics 2015, 9, 031301. [CrossRef] [PubMed]

21. Cohn, J.R.; Emmett, E.A. The Excretion of trace metals in human sweat. Ann. Clin. Lab. Sci. 1978, 8, $270-275$.

22. Sears, M.E.; Kerr, K.J.; Bray, R.I. Arsenic, Cadmium, Lead, and Mercury in Sweat: A Systematic Review. J. Environ. Public Health 2012, 2012, 184745. [CrossRef] [PubMed]

23. Mudgal, V.; Madaan, N.; Mudgal, A.; Singh, R.B.; Mishra, S. Effect of toxic metals on human health. Open Nutraceuticals J. 2010, 3, 94-99. [CrossRef]

24. Fraga, C.G. Relevance, Essentiality and Toxicity of Trace Elements in Human Health. Mol. Asp. Med. 2005, 26, 235. [CrossRef]

25. Wang, S.; Wu, Y.; Gu, Y.; Li, T.; Luo, H.; Li, L.-H.; Bai, Y.; Li, L.; Liu, L.; Cao, Y.; et al. Wearable sweatband sensor platform based on gold nanodendrite array as efficient solid contact of ion-selective electrode. Anal. Chem. 2017, 89, 10224-10231. [CrossRef]

26. Deshmukh, M.A.; Shirsat, M.D.; Ramanaviciene, A.; Ramanavicius, A. Composites based on conducting polymers and carbon nanomaterials for heavy metal ion sensing (Review). Crit. Rev. Anal. Chem. 2018, 48, 293-304. [CrossRef] [PubMed] 
27. Xuan, X.; Hussain, F.; Park, J.Y. A Fully integrated and miniaturized heavy-metal-detection sensor based on micropatterned reduced graphene oxide. Sci. Rep. 2016, 6, 33125. [CrossRef]

28. Zhao, G.; Si, Y.; Wang, H.; Liu, G. A portable electrochemical detection system based on graphene/ionic liquid modified screen-printed electrode for the detection of cadmium in soil by square wave anodic stripping voltammetry. Int. J. Electrochem. Sci. 2016, 11, 54-64.

29. ALOthman, Z.; Alam, M.; Naushad, M.; Bushra, R. Electrical conductivity and thermal stability studies on polyaniline Sn(IV) tungstomolybdate nanocomposite cation-exchange material: Applicatinas $\mathrm{Pb}$ (II) ion-selective membrane electrode. Int. J. Electrochem. Sci. 2015, 10, 2663-2684.

30. Tarabek, A.; Rapta, P.; Jahne, E.; Ferse, D.; Adler, H.; Maumy, M.; Dunsch, L. Spectroelectrochemical and potentiometric studies of functionalised electroactive polymers. Electrochim. Acta 2005, 50, 1643-1651. [CrossRef]

31. Dobson, J.; Snodin, P.R.; Thirsk, H.R. EMF measurements of cells employing metal—metal oxide electrodes in aqueous chloride and sulphate electrolytes at temperatures between $25-250^{\circ} \mathrm{C}$. Electrochim. Acta 1976, 21, 527-533. [CrossRef]

32. Tseng, P.; Napier, B.; Garbarini, L.; Kaplan, D.L.; Omenetto, F.G. Functional, RF-trilayer sensors for tooth-mounted, wireless monitoring of the oral cavity and food consumption. Adv. Mater. 2018, 30, 201703257. [CrossRef] [PubMed]

33. Magri, D.C.; Fava, M.C.; Mallia, C.J. A sodium-enabled 'Pourbaix sensor': A three-input AND logic gate as a 'lab-on-a-molecule' for monitoring $\mathrm{Na}^{+}, \mathrm{pH}$ and pE. Chem. Commun. 2014, 50, 1009-1011. [CrossRef] [PubMed]

34. Skalska, J.; Bednarczyk, P.; Piwońska, M.; Kulawiak, B.; Wilczynski, G.; Dołowy, K.; Kunz, W.S.; Kudin, A.P.; Szewczyk, A. Calcium ions regulate $\mathrm{K}^{+}$uptake into brain mitochondria: The evidence for a novel potassium channel. Int. J. Mol. Sci. 2009, 10, 1104. [CrossRef] [PubMed]

35. Li, H.; Zhu, Y.; Islam, M.S.; Rahman, M.A.; Walsh, K.B.; Koley, G. Graphene field effect transistors for highly sensitive and selective detection of $\mathrm{K}^{+}$ions. Sens. Actuators B 2017, 253, 759-765. [CrossRef]

36. Aicher, M.; Grothe, H.; Wolf, B. A novel thin film impedance Ca ion sensor for drinking water. Sens. Actuators $B$ 2017, 244, 1103-1112. [CrossRef]

37. Ndobo-Epoy, J.-P.; Lesniewska, E.; Guicquero, J.-P. Nano-pH sensor for the study of reactive materials. Anal. Chem. 2007, 79, 7560-7564. [CrossRef] [PubMed]

38. Huang, W.-D.; Cao, H.; Deb, S.; Chiao, M.; Chiao, J.C. A flexible pH sensor based on the iridium oxide sensing film. Sens. Actuators A 2011, 169, 1-11. [CrossRef]

39. Zhu, L.; Miao, M.; Shao, X.; Du, Z.; Huang, K.; Luo, Y.; Xu, W. A universal electrochemical biosensor using nick-HCR nanostructure as molecular gate of nanochannel for detecting chromium (III) ions and microRNA. Anal. Chem. 2019, 91, 14992-14999. [CrossRef]

40. Gao, W.; Nyein, H.Y.Y.; Shahpar, Z.; Fahad, H.M.; Chen, K.; Emaminejad, S.; Gao, Y.; Tai, L.-C.; Ota, H.; Wu, E.; et al. Wearable microsensor array for multiplexed heavy metal monitoring of body fluids. ACS Sens. 2016, 1, 866-874. [CrossRef]

41. Liu, J.; Lu, W.; Zhang, L.; Yang, J.; Yao, Z.-P.; He, Y.; Li, Y. Integrated hand-held electrochemical sensor for multicomponent detection in urine. Biosens. Bioelectron. 2021, 193, 113534. [CrossRef] [PubMed]

42. Goud, K.Y.; Teymourian, H.; Sandhu, S.S.; Tostado, N.; Mishra, R.K.; Moore, L.C.; Harvey, S.P.; Wang, J. OPAA/fluoride biosensor chip towards field detection of G-type nerve agents. Sens. Actuators B 2020, 320, 128344. [CrossRef]

43. Kataev, E.A.; Müller, C. Recent advances in molecular recognition in water: Artificial receptors and supramolecular catalysis. Tetrahedron 2014, 70, 137-167. [CrossRef]

44. Gołebiewski, P.; Puciłowski, B.; Sommer, F.; Kubik, S.; Daniels, M.; Dehaen, W.; Sivasankaran, U.; Kumar, K.G.; Radecka, H.; Radecki, J. Electrochemical sensing of sulfate in aqueous solution with a cyclopeptide-dipyrromethene-Cu (II) or Co (II) complex attached to a gold electrode. Sens. Actuators B 2019, 285, 536-545. [CrossRef]

45. Emaminejad, S.; Gao, W.; Wu, E.; Davies, Z.A.; Nyein, H.Y.Y.; Challa, S.; Ryan, S.P.; Fahad, H.M.; Chen, K.; Shahpar, Z.; et al. Autonomous sweat extraction and analysis applied to cystic fibrosis and glucose monitoring using a fully integrated wearable platform. Proc. Natl. Acad. Sci. USA 2017, 114, 4625-4630. [CrossRef] [PubMed]

46. Ali, M.A.; Wang, X.; Chen, Y.; Jiao, Y.; Mahal, N.K.; Moru, S.; Castellano, M.J.; Schnable, J.C.; Schnable, P.S.; Dong, L. Continuous monitoring of soil nitrate using a miniature sensor with poly(3-octyl-thiophene) and molybdenum disulfide nanocomposite. ACS Appl. Mater. Interfaces 2019, 11, 29195-29206. [CrossRef] [PubMed]

47. Bhata, K.S.; Ahmadb, R.; Mahmoudia, T.; Hahn, Y.-B. High performance chemical sensor with field-effect transistors array for selective detection of multiple ions. Chem. Eng. J. 2021, 417, 128064. [CrossRef]

48. Mahajan, R.K.; Kaur, I.; Kumar, M. Silver ion-selective electrodes employing Schiff base p-tert-butyl calix[4]arene derivatives as neutral carriers. Sens. Actuators B Chem. 2003, 91, 26-31. [CrossRef]

49. Nyein, H.Y.Y.; Tai, L.-C.; Ngo, Q.P.; Chao, M.; Zhang, G.B.; Gao, W.; Bariya, M.; Bullock, J.; Kim, H.; Fahad, H.M.; et al. A wearable microfluidic sensing patch for dynamic sweat secretion analysis. ACS Sens. 2018, 3, 944-952. [CrossRef]

50. El-Shishtawy, R.M.; Al-Ghamdi, H.A.; Alam, M.M.; Al-amshany, Z.M.; Asiri, A.; Rahman, M.M. Development of Cd ${ }^{2+}$ sensor based on BZNA/Nafion/Glassy carbon electrode by electrochemical approach. Chem. Eng. J. 2018, 352, 225-231. [CrossRef]

51. Sakthinath, S.; Tamizhdurai, P.; Ramesh, A.; Chi, T.W.; Mangesh, V.L.; Veerarajan, S.; Shanthi, K. Platinum incorporated mordenite zeolite modified glassy carbon electrode used for selective electrochemical detection of mercury ions. Microporous Mesoporous Mater. 2020, 292, 109770. [CrossRef] 
52. Nguyen, L.D.; Doan, T.C.D.; Huynh, T.M.; Nguyen, V.N.P.; Dinh, H.H.; Dang, D.M.T.; Dang, C.M. An electrochemical sensor based on polyvinyl alcohol/chitosan-thermally reduced graphene composite modified glassy carbon electrode for sensitive voltammetric detection of lead. Sens. Actuators B. 2021, 345, 130443. [CrossRef]

53. Fu, R.; Yu, P.; Wang, M.; Sun, J.; Chen, D.; Jin, C.Y.; Li, Z.L. The research of lead ion detection based on rGO/g-C3N4 modified glassy carbon electrode. Microchem. J. 2020, 157, 105076. [CrossRef]

54. Phal, S.; Nguyễn, H.; Berisha, A.; Tesfalidet, S. In situ Bi/carboxyphenyl-modified glassy carbon electrode as a sensor platform for detection of $\mathrm{Cd}^{2+}$ and $\mathrm{Pb}^{2+}$ using square wave anodic stripping voltammetry. Sens. Bio-Sens. Res. 2021, 34, 100455. [CrossRef]

55. Shah, A.; Nisar, A.; Khan, K.; Nisar, J.; Niaz, A.; Ashiq, M.N.; Akhter, M.S. Amino acid functionalized glassy carbon electrode for the simultaneous detection of thallium and mercuric ions. Electrochim. Acta 2019, 321, 134658. [CrossRef]

56. Shivappa Adarakatti, P.; Foster, C.W.; Banks, C.E.; Malingappa, P. Calixarene bulk modified screen-printed electrodes (SPCCEs) as a one-shot disposable sensor for the simultaneous detection of lead(II), copper(II) and mercury(II) ions: Application to environmental samples. Sens. Actuators A Phys. 2017, 267, 517-525. [CrossRef]

57. Awad Ali, T.; Abd-Elaal, A.A.; Mohamed, G.G. Screen printed ion selective electrodes based on self-assembled thiol surfactantgold-nanoparticles for determination of $\mathrm{Cu}$ (II) in different water samples. Microchem. J. 2021, 160, 105693. [CrossRef]

58. Núñez, C.; Triviño, J.J.; Arancibia, V. A electrochemical biosensor for As(III) detection based on the catalytic activity of Alcaligenes faecalis immobilized on a gold nanoparticle-modified screen-printed carbon electrode. Talanta Open 2021, 223, 121702. [CrossRef] [PubMed]

59. Tapia, M.A.; Pérez-Ràfols, C.; Gusmão, R.; Serrano, N.; Sofer, Z.; Díaz-Cruz, J.M. Enhanced voltammetric determination of metal ions by using a bismuthene-modified screen-printed electrode. Electrochim. Acta 2020, 362, 137144. [CrossRef]

60. Mazzaracchio, V.; Serani, A.; Fiore, L.; Moscone, D.; Arduini, F. All-solid state ion-selective carbon black-modified printed electrode for sodium detection in sweat. Electrochim. Acta 2021, 394, 139050. [CrossRef]

61. Honeychurch, K.C.; Hart, J.P. Screen-printed electrochemical sensors for monitoring metal pollutants. TrAC Trends Anal. Chem. 2003, 22, 456-469. [CrossRef]

62. Hart, J.P.; Crew, A.; Crouch, E.; Honeychurch, K.C.; Arun Kumar, N.S.; Pembelton, R.M. Some recent designs and developments of screen-printed carbon electrochemical sensors/biosensors for biomedical, environmental, and industrial analyses. Anal. Lett. 2004, 37, 789-830. [CrossRef]

63. Zielińska, R.; Mulik, E.; Michalska, A.; Achmatowicz, S.; Maj-Żurawska, M. All-solid-state planar miniature ion-selective chloride electrode. Anal. Chim. Acta 2002, 451, 243-249. [CrossRef]

64. Tymecki, L.; Glab, S.; Koncki, R. Miniaturized, planar ion-selective electrodes fabricated by means of thick-film technology. Sensors 2006, 6, 390-396. [CrossRef]

65. Suherman, A.L.; Rasche, B.; Godlewska, B.; Nicholas, P.; Herlihy, S.; Caiger, N.; Cowen, P.J.; Compton, R.G. Electrochemical detection and quantification of lithium ions in authentic human saliva using $\mathrm{LiMn}_{2} \mathrm{O}_{4}$-modified electrodes. ACS Sens. 2019, 4, 2497-2506. [CrossRef]

66. Bergveld, P. Development of an Ion-Sensitive Solid-State Device for Neurophysiological Measurements. IEEE Trans. Biomed. Eng. 1970, 17, 70-71. [CrossRef]

67. Vlascici, D.; Fagadar-Cosma, E.; Popa, I.; Chiriac, V.; Gil-Agusti, M. A novel sensor for monitoring of iron (III) ions based on porphyrins. Sensors 2012, 12, 8193-8203. [CrossRef]

68. Liang, T.; Jiang, N.; Zhou, S.; Wang, X.; Xu, Y.; Wu, C.; Kirsanov, D.; Legin, A.; Wan, H.; Wang, P. Multiplexed all-solid-state ion-sensitive light-addressable potentiometric sensor (ISLAPS) system based on silicone-rubber for physiological ions detection Anal. Chim. Acta 2021, 1179, 338603. [CrossRef]

69. Dębosz, M.; Wieczorek, M.; Paluch, J.; Migdalski, J.; Baś, B.; Kościelniak, P. 3D-printed flow manifold based on potentiometric measurements with solid-state ion-selective electrodes and dedicated to multicomponent water analysis. Talanta Open $\mathbf{2 0 2 0}$ 217, 121092. [CrossRef]

70. Cazalé, A.; Sant, W.; Ginot, F.; Launay, J.C.; Savourey, G.; Revol-Cavalier, F.; Lagarde, L.M.; Heinry, D.; Launay, J.; Temple-Boyer, P. Physiological stress monitoring using sodium ion potentiometric microsensors for sweat analysis. Sens. Actuators B 2016, 225, 1-9. [CrossRef]

71. Zhai, J.; Zhang, Y.; Zhao, D.; Kou, L.; Zhao, G. In vivo monitoring of calcium ions in rat cerebrospinal fluid using an all-solid-state acupuncture needle based potentiometric microelectrode. Anal. Chim. Acta 2021, 23, 339209. [CrossRef]

72. Hou, X.; Xiong, B.; Wang, Y.; Wang, L.; Wang, H. Determination of trace lead and cadmium in decorative material using disposable screen-printed electrode electrically modified with reduced graphene oxide/L-cysteine/Bi-film. Sensors 2020, 20, 1322. [CrossRef]

73. Chen, L.-D.; Wang, W.-J.; Wang, G.-J. Electrochemical detection of electrolytes using a solid-state ion-selective electrode of single-piece type membrane. Biosensors 2021, 11, 109. [CrossRef]

74. Wang, J.; Hu, J.; Hu, S.; Gao, G.; Song, Y. A novel electrochemical sensor based on electropolymerized ion imprinted PoPD/ERGO composite for trace Cd(II) determination in water. Sensors 2020, 20, 1004. [CrossRef]

75. Hamsawahini, K.; Sathishkumar, P.; Ahamad, R.; Yusoff, A.R.M. A sensitive, selective, and rapid determination of lead (II) ions in real-life samples using an electrochemically reduced graphene oxide-graphite reinforced carbon electrode. Talanta 2015, 144, 969-976. [CrossRef] 
76. El-Desoky, H.S.; Beltagi, A.M.; Ghoneim, M.M.; EI-Hadad, A.I. The first utilization of graphene nano-sheets and synthesized $\mathrm{Fe}_{3} \mathrm{O}_{4}$ nanoparticles as a synergistic electrodeposition platform for simultaneous voltammetric determination of some toxic heavy metal ions in various real environmental water samples. Microchem. J. 2021, 175, 106966. [CrossRef]

77. Tyszczuk-Rotko, K. Metal film electrodes prepared with a reversibly deposited mediator in voltammetric analysis of metal ions. Curr. Opin. Electrochem. 2019, 17, 128-133. [CrossRef]

78. Li, L.; Qiu, Y.; Feng, Y.; Li, Y.; Wu, K.; Zhu, L. Stripping voltammetric analysis of mercury ions at nitrogen-doped reduced graphene oxide modified electrode. J. Electroanal. Chem. 2020, 865, 114121. [CrossRef]

79. Jian, J.-M.; Liu, Y.-Y.; Zhang, Y.-L.; Guo, X.-S.; Cai, Q. Fast and sensitive detection of $\mathrm{Pb}^{2+}$ in foods using disposable screen-printed electrode modified by reduced graphene oxide. Sensors 2013, 13, 13063-13075. [CrossRef]

80. Willemse, C.M.; Tlhomelang, K.; Jahed, N.; Baker, P.G.; Iwuoha, E.I. Metallo-graphene nanocomposite electrocatalytic platform for the determination of toxic metal ions. Sensors 2011, 11, 3970-3987. [CrossRef]

81. Nyein, H.Y.Y.; Gao, W.; Shahpar, Z.; Emaminejad, S.; Challa, S.; Chen, K.; Fahad, H.M.; Tai, L.-C.; Ota, H.; Davis, R.W.; et al. A wearable electrochemical platform for noninvasive simultaneous monitoring of $\mathrm{Ca}^{2+}$ and $\mathrm{pH}$. ACS Nano 2016, 10, 7216-7224. [CrossRef]

82. Gao, W.; Emaminejad, S.; Nyein, H.Y.Y.; Challa, S.; Chen, K.; Peck, A.; Fahad, H.M.; Ota, H.; Shiraki, H.; Kiriya, D.; et al. Fully integrated wearable sensor arrays for multiplexed in situ perspiration analysis. Nature 2016, 529, 509. [CrossRef]

83. Lee, Y.; Howe, C.; Mishra, S.; Lee, D.S.; Mahmood, M.; Piper, M.; Kim, Y.; Tieu, K.; Byun, H.-S.; Coffey, J.P.; et al. Wireless, intraoral hybrid electronics for real-time quantification of sodium intake toward hypertension management. Proc. Natl. Acad. Sci. USA 2018, 115, 5377-5382. [CrossRef] [PubMed]

84. Bianchi, M.; Haschke, R.; Büscher, G.; Ciotti, S.; Carbonaro, N.; Tognetti, A. A Multi-modal sensing glove for human manualinteraction studies. Electronics 2016, 5, 42. [CrossRef]

85. Jong, M.D.; Sleegers, N.; Kim, J.; Durme, F.V.; Samyn, N.; Wang, J.; Wael, K.D. Electrochemical fingerprint of street samples for fast on-site screening of cocaine in seized drug powders. Chem. Sci. 2016, 7, 2364-2370. [CrossRef]

86. Bandodkar, A.J.; O’Mahony, A.M.; Ramírez, J.; Samek, I.A.; Anderson, S.M.; Windmiller, J.R.; Wang, J. Solid-state forensic finger sensor for integrated sampling and detection of gunshot residue and explosives: Towards 'Lab-on-a-finger'. Analyst 2013, 138, 5288-5295. [CrossRef] [PubMed]

87. Mishra, R.K.; Hubble, L.J.; Martín, A.; Kumar, R.; Barfidokht, A.; Kim, J.; Musameh, M.M.; Kyratzis, I.L.; Wang, J. Wearable flexible and stretchable glove biosensor for on-site detection of organophosphorus chemical threats. ACS Sens. 2017, 2, 553-561. [CrossRef]

88. Bariya, M.; Li, L.; Ghattamaneni, R.; Ahn, C.H.; Nyein, H.Y.Y.; Tai, L.-C.; Javey, A. Glove-based sensors for multimodal monitoring of natural sweat. Sci. Adv. 2020, 6, eabb8308. [CrossRef]

89. Hao, J.; Li, X.-Y.; Zhang, Y.; Dong, W.-K. A Reversible Bis(Salamo)-based fluorescence sensor for selective detection of Cd ${ }^{2+}$ in water-containing systems and food samples. Materials 2018, 11, 523. [CrossRef]

90. Ma, Z.; Chen, P.; Cheng, W.; Yan, K.; Pan, L.; Shi, Y.; Yu, G. Highly sensitive, printable nanostructured conductive polymer wireless sensor for food spoilage detection. Nano Lett. 2018, 18, 4570-4575. [CrossRef]

91. Schaude, C.; Meindl, C.; Fröhlich, E.; Attard, J.; Mohr, G.J. Developing a sensor layer for the optical detection of amines during food spoilage. Talanta 2017, 170, 481-487. [CrossRef] [PubMed]

92. Wang, J.; Yang, Q.; Zhang, L.; Liu, M.; Hu, N.; Zhang, W.; Zhu, W.; Wang, R.; Suo, Y.; Wang, J. A hybrid monolithic column based on layered double hydroxide-alginate hydrogel for selective solid phase extraction of lead ions in food and water samples. Food Chem. 2018, 257, 155-162. [CrossRef] [PubMed]

93. Kim, H.J.; Hummel, J.W.; Sudduth, K.A.; Birrell, S.J. Evaluation of phosphate ion-selective membranes and cobalt-based electrodes for soil nutrient sensing. Trans. ASABE 2007, 50, 415-425. [CrossRef]

94. Sasaki, S.; Ozawa, S.; Citterio, D.; Yamada, K.; Suzuki, K. Organic tin compounds combined with anionic additives-An ionophore system leading to a phosphate ion-selective electrode. Talanta 2004, 63, 131-134. [CrossRef] [PubMed]

95. Kivlehan, F.; Mace, W.J.; Moynihan, H.A.; Arrigan, D.W.M. Potentiometric evaluation of calix[4]arene anion receptors in membrane electrodes: Phosphate detection. Anal. Chim. Acta 2007, 585, 154-160. [CrossRef]

96. Jiang, H.; Ali, M.A.; Jiao, Y.; Yang, B.; Dong, L. In-situ, real-time monitoring of nutrient uptake on plant chip integrated with nutrient sensor. In Proceedings of the International Conference on Solid-State Sensors, Actuators and Microsystems (TRANSDUCERS), Kaohsiung, Taiwan, 18-22 June 2017; IEEE: Kaohsiung, Taiwan, 2017.

97. Ruecha, N.; Chailapakul, O.; Suzuki, K.; Citterio, D. Fully inkjet-printed paper-based potentiometric ion-sensing devices. Anal. Chem. 2017, 89, 10608-10616. [CrossRef]

98. Kim, H.-J.; Sudduth, K.A.; Hummel, J.W. Soil macronutrient sensing for precision agriculture. J. Environ. Monit. 2009, 11, 1810-1824. [CrossRef]

99. Garland, N.T.; McLamore, E.S.; Cavallaro, N.D.; Mendivelso-Perez, D.; Smith, E.A.; Jing, D.; Claussen, J.C. Flexible laser-induced graphene for nitrogen sensing in soil. ACS Appl. Mater. Interfaces 2018, 10, 39124-39133. [CrossRef] [PubMed]

100. Wei, P.; $\mathrm{Li}$, Z.; Zhao, X.; Song, R.; Zhu, Z. $\mathrm{Fe}_{3} \mathrm{O}_{4} / \mathrm{SiO}_{2} / \mathrm{CS}$ surface ion-imprinted polymer modified glassy carbon electrode for highly sensitivity and selectivity detection of toxic metal ions. J. Taiwan Inst. Chem. Eng. 2020, 113, 107-113. [CrossRef]

101. Hu, H.; Lu, W.; Liu, X.; Meng, F.; Zhu, J. A high-response electrochemical As(III) sensor using $\mathrm{Fe}_{3} \mathrm{O}_{4}-\mathrm{rGO} \mathrm{Canocomposite}$ materials. Chemosensors 2021, 9, 150. [CrossRef] 
102. Duruibe, J.O.; Ogwuegbu, M.O.C.; Egwurugwu, J.N. Heavy Metal Pollution and Human Biotoxic Effects. Int. J. Phys. Sci. 2007, 2, 112-118.

103. Krizkova, S.; Krystofova, O.; Trnkova, L.; Hubalek, J.; Adam, V.; Beklova, M.; Horna, A.; Havel, L.; Kizek, R. Silver(I) ions ultrasensitive detection at carbon electrodes-Analysis of waters, tobacco cells and fish tissues. Sensors 2009, 9, 6934-6950. [CrossRef]

104. Song, Y.; Min, J.; Yu, Y.; Wang, H.; Yang, Y.; Zhang, H.; Gao, W. Wireless battery-free wearable sweat sensor powered by human motion. Sci. Adv. 2020, 6, eaay9842. [CrossRef]

105. Sharma, H.; Haque, A.; Jaffery, Z.A. Solar energy harvesting wireless sensor network nodes: A survey. J. Renew. Sustain. Energy 2018, 10, 023704. [CrossRef]

106. Jeerapan, I.; Sempionatto, J.R.; Pavinatto, A.; You, J.-M.; Wang, J. Stretchable biofuel cells as wearable textile-based self-powered sensors. J. Mater. Chem. A 2016, 4, 18342-18353. [CrossRef]

107. Lee, H.U.K.; Yoo, H.Y.; Lkhaqvasuren, T.; Song, Y.S.; Park, C.; Kim, J.; Kim, S.W. Enzymatic fuel cells based on electrodeposited graphite oxide/cobalt hydroxide/chitosan composite-enzyme electrode. Biosens. Bioelectron. 2013, 42, 342-348. [CrossRef] [PubMed]

108. Yu, Y.; Nassar, J.; Xu, C.; Min, J.; Yang, Y.; Dai, A.; Doshi, R.; Huang, A.; Song, Y.; Gehlhar, R.; et al. Biofuel-powered soft electronic skin with multiplexed and wireless sensing for human-machine interfaces. Sci. Robot. 2020, 5, eaaz7946. [CrossRef] [PubMed]

109. Renewables Global Status Report. Available online: http:/ /www.ren21.net/status-of-renewables/global-status-report/ (accessed on 28 July 2018).

110. Gong, J.; Sumathy, K.; Qiao, Q.; Zhou, Z. Review on dye-sensitized solar cells (DSSCs): Advanced techniques and research trends. Renew. Sustain. Energy Rev. 2017, 68, 234-246. [CrossRef]

111. Bittner, F.; Oekermann, T.; Wark, M. Scale-up of the electrodeposition of ZnO/Eosin y hybrid thin films for the fabrication of flexible dye-sensitized solar cell modules. Materials 2018, 11, 232. [CrossRef]

112. Juhász Junger, I.; Wehlage, D.; Böttjer, R.; Grothe, T.; Juhász, L.; Grassmann, C.; Blachowicz, T.; Ehrmann, A. Dye-sensitized solar cells with electrospun nanofiber mat-based counter electrodes. Materials 2018, 11, 1604. [CrossRef] [PubMed]

113. Hashmi, S.G.; Martineau, D.; Li, X.; Ozkan, M.; Tiihonen, A.; Dar, M.I.; Sarikka, T.; Zakeeruddin, S.M.; Paltakari, J.; Lund, P.D.; et al. Air processed inkjet infiltrated carbon based printed perovskite solar cells with high stability and reproducibility. Adv. Mater. Technol. 2016, 2, 1600183. [CrossRef]

114. Hashmi, S.G.; Ozkan, M.; Halme, J.; Misic, K.D.; Zakeeruddin, S.M.; Paltakari, J.; Grätzel, M.; Lund, P.D. High performance dye-Sensitized solar cells with inkjet printed ionic liquid electrolyte. Nano Energy 2015, 17, 206-215. [CrossRef]

115. Hagfeldt, L.; Boschloo, G.; Sun, L.; Kloo, L.; Pettersson, H. Dye-sensitized solar cells. Chem. Rev. 2010, 110, 6595. [CrossRef]

116. Agrawal, K.L.; Shtein, M. Self-powered ion detectors based on dye-sensitized photovoltaics. Nanoscale 2014, 6, 11019-11023. [CrossRef] [PubMed]

117. Bell, L.E. Cooling, heating, generating power, and recovering waste heat with thermoelectric systems. Science 2008, 321, 1457-1461.

118. Snyder, G.J.; Toberer, E.S. Complex thermoelectric materials. Nat. Mater. 2008, 7, 105-114. [CrossRef]

119. Tsao, Y.H.; Husain, R.A.; Lin, Y.-J.; Khan, I.; Chen, S.-W.; Lin, Z.-H. A self-powered mercury ion nanosensor based on the thermoelectric effect and chemical transformation mechanism. Nano Energy 2019, 62, 268-274. [CrossRef]

120. Wang, Z.L.; Chen, J.; Lin, L. Progress in triboelectric nanogenerators as a new energy technology and self-powered sensors. Energy Environ. Sci. 2015, 8, 2250-2282.

121. Wang, Z.L. Triboelectric nanogenerators as new energy technology for self-powered systems and as active mechanical and chemical sensor. ACS Nano 2013, 7, 9533-9557. [CrossRef] [PubMed] 